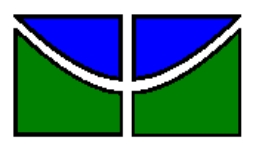

Universidade de Brasília (UnB)

Faculdade de Economia, Administração e Contabilidade (FACE)

Programa de Pós-Graduação em Administração (PPGA)

Curso de Mestrado Acadêmico em Administração

\title{
INOVAÇÃO NA GESTÃO PÚBLICA FEDERAL: ANÁLISE DAS RELAÇÕES ENTRE CAPACIDADES, MODOS E RESULTADOS DA INOVAÇÃO
}

\author{
EDUARDO LUIS LAFETÁ DE OLIVEIRA
}

Orientador: Prof. Dr. Antônio Isidro da Silva Filho

Dissertação de Mestrado 
Oliveira, Eduardo Luis Lafetá de

INOVAÇÃO NA GESTÃO PÚBLICA FEDERAL: Análise das relações entre capacidades, modos e resultados da inovação / Eduardo Luis Lafetá de Oliveira; orientador Antônio Isidro da Silva Filho. - Brasília, 2017.

$72 \mathrm{p}$.

Dissertação (Mestrado- Mestrado em Administração) - Universidade de Brasília, 2017.

1. Administração Pública Federal. 2. Inovação em Serviços. 3. Serviços Públicos. 4. Prêmio de Inovação. I. Isidro-Filho, Antônio, orient. II. Inovação na gestão pública federal: Análise das relações entre capacidades, modos e resultados da inovação. III. Universidade de Brasília 


\section{INOVAÇÃO NA GESTÃo PÚBLICA FEDERAL: ANÁLISE DAS RELAÇÕES ENTRE CAPACIDADES, MODOS E RESULTADOS DE INOVAÇÃO}

\section{EDUARDO LUIS LAFETÁ DE OLIVEIRA}

Comissão Examinadora:

Dissertação submetida ao Programa de PósGraduação em Administração (PPGA) da Universidade de Brasília como requisito parcial à obtenção do grau de Mestre em Administração.

Prof. Dr. Antônio Isidro da Silva Filho, Universidade de Brasília (PPGA/UnB)

Orientador

Profa. Dra. Marina Figueiredo Moreira, Universidade de Brasília (PPGA/UnB)

Examinadora Interna

Prof. Dr. André Luiz Marques Serrano (PPGCONT/UnB)

Examinador Externo

Prof. Dr. Rafael Barreiros Porto, Universidade de Brasília (PPGA/UnB)

Suplente 


\section{Resumo}

O presente trabalho examinou os efeitos dos modos, capacidades e resultados de inovação em relação aos resultados de inovação no Poder Executivo Federal. Para alcançar os objetivos da pesquisa foram analisados relatos de experiências premiadas no concurso de inovação da Escola Nacional de Administração Pública - ENAP, no período de 1999 a 2014. Uma análise de conteúdo foi efetuada nos relatos das experiências finalistas para codificar e categorizar os dados de interesse da pesquisa que são: modos, capacidades e resultados de inovação, sendo codificados de forma binária (presença ou ausência). Com base em modelos internacionais de inovação pública foi elaborado um modelo para este trabalho para testar três hipóteses, por meio de regressão logística. A primeira hipótese é que a presença de modos de inovação aumenta a probabilidade de ocorrência de resultados da inovação. A segunda hipótese e a presença de capacidade de inovação aumenta a probabilidade de modos de inovação. A terceira hipótese é que a presença de modos de inovação e capacidades de inovação aumenta a probabilidade de ocorrência de resultados da inovação. Algumas capacidades associadas com modo de inovação influenciaram positivamente os resultados de inovação, também foi observado que a capacidade de inovação influência positivamente os modos de inovação. Contudo, foram observados que alguns previsores diminuem a ocorrência dos resultados esperados.

Palavras-chave: Administração Pública Federal, Inovação em Serviços, Setor Público, Prêmio de Inovação 


\begin{abstract}
The present research examined the effects of the modes, capabilities and results of innovation in relation to the results of innovation in the Federal Public Management. In order to reach the objectives of the research, we analyzed reports of experiences awarded in the innovation contest of the National School of Public Administration - ENAP, from 1999 to 2014. A content analysis was carried out in the reports of the finalist experiments to codify and categorize the data of Research, which are: modes, capabilities and innovation results, being encoded binary (presence or absence). Based on international models of public innovation, a model for this work was developed to test three hypotheses through logistic regression. The first hypothesis is that the presence of modes of innovation increases the probability of occurrence of innovation results. The second hypothesis and the presence of innovation capabilities increases the probability of innovation modes. The third hypothesis is that the presence of innovation modes and innovation capabilities increases the probability of innovation results. Some capabilities associated with innovation mode positively influenced the results of innovation, it was also observed that the capacity for innovation positively influences the modes of innovation. However, it was observed that some predictors decrease the occurrence of the expected results.
\end{abstract}

Keywords: Federal Public Administration, Innovation in Services, Public Sector, Innovation Prize 


\section{Lista de Figuras}

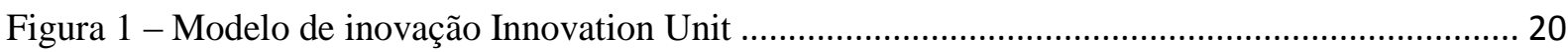

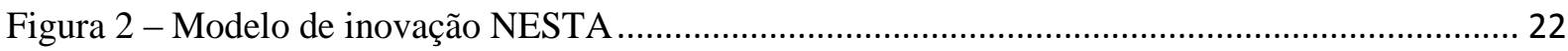

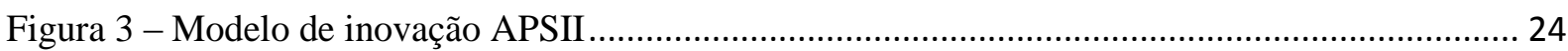

Figura 4 - Modelo heurístico de inovação do setor público ............................................................... 25

Figura 5 - A forma mais geral do produto como um sistema de características e competências ......... 29

Figura 6 - Produto e serviço como uma conjunção de características e competências.......................... 30

Figura 7 - Modelo estrutural da pesquisa ................................................................................. 36

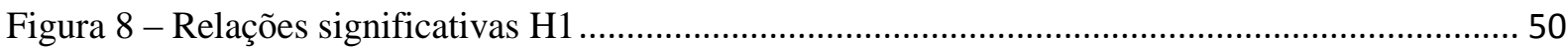

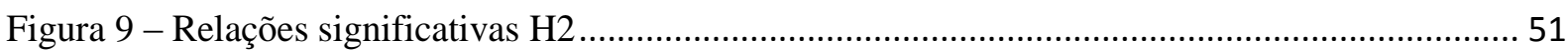

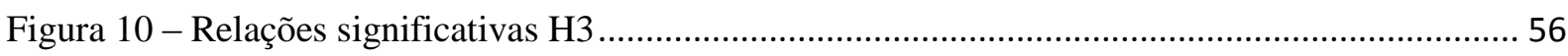




\section{Lista de Quadros}

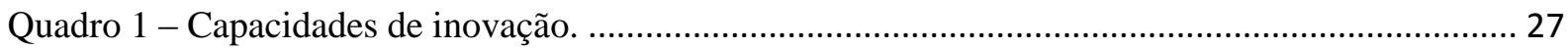

Quadro 2 - Tipologia de inovação em serviços. ........................................................................... 30

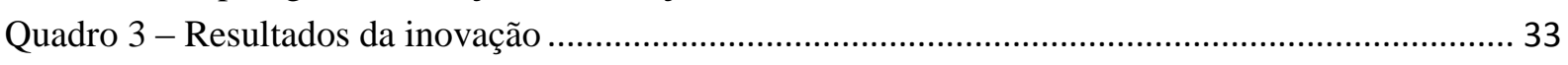

Quadro 4 - Referências das hipóteses ........................................................................................ 36

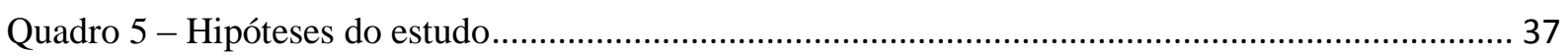

Quadro 6 - Cruzamento de informações entre frequências de capacidades e resultado de H3. ........... 57

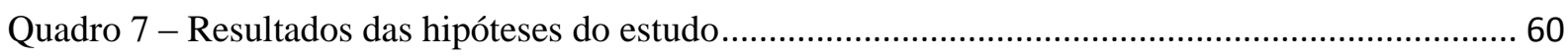




\section{Lista de Tabelas}

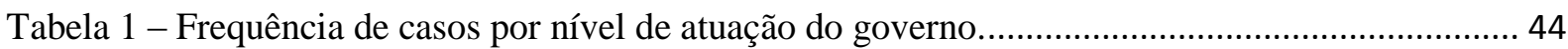

Tabela 2 - Frequência de casos pela estrutura da administração …....................................................... 44

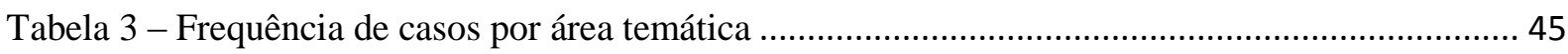

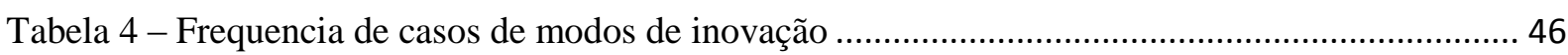

Tabela 5 - Frequência de casos de capacidade de inovação ................................................................ 47

Tabela 6 - Frequência de casos de resultados de inovação................................................................. 48

Tabela 7 - A presença de modos de inovação aumenta a probabilidade de ocorrência de inovação na

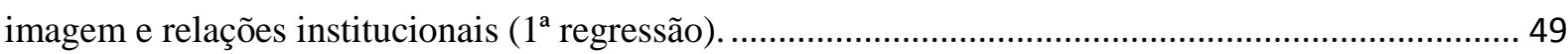

Tabela 8 - A presença de capacidade de inovação aumenta a probabilidade de uma inovação

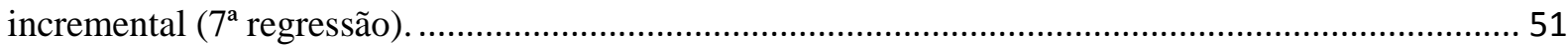

Tabela 9 - A presença de modos de inovação e capacidades de inovação aumentam a probabilidade de ocorrência de inovação na imagem e relações institucionais. ( $8^{\mathrm{a}}$ regressão).

Tabela 10 - A presença de modos de inovação e capacidades de inovação aumentam a probabilidade de ocorrência na entrega e/ou qualidade dos serviços. ( $9^{\mathrm{a}}$ regressão)................................................ 53

Tabela 11 - A presença de modos de inovação e capacidades de inovação aumentam a probabilidade de ocorrência de gestão organizacional $\left(10^{\mathrm{a}}\right.$ regressão)

Tabela 12 - A presença de modos de inovação e capacidades de inovação aumentam a probabilidade de ocorrência de clima organizacional ( $11^{\mathrm{a}}$ regressão) 


\section{Sumário}

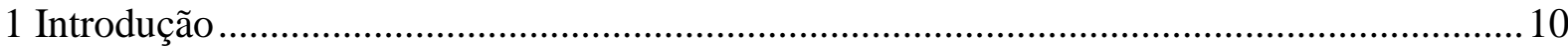

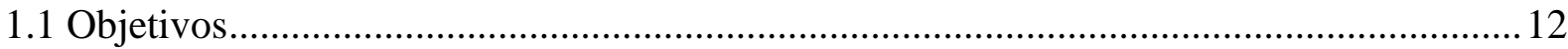

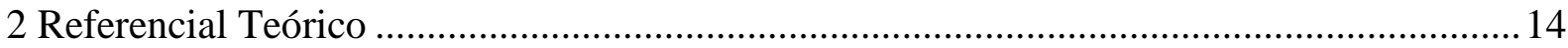

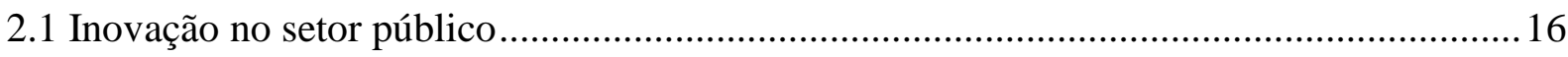

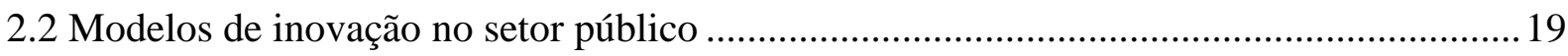

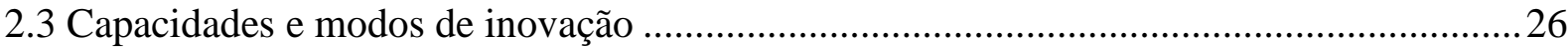

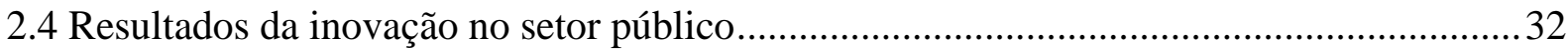

2.5 Modelo teórico da pesquisa .........................................................................................33

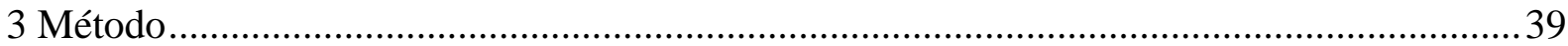

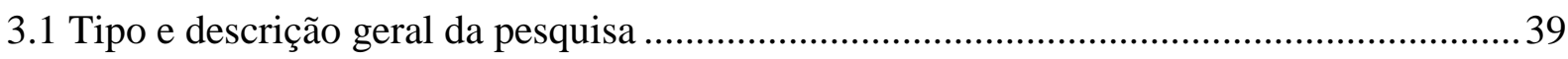

3.2 População, amostra e participantes do estudo ................................................................... 40

3.3 Procedimento de análise de dados .............................................................................

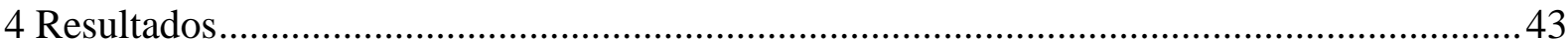

4.1 Análise descritiva das experiências ...............................................................................4

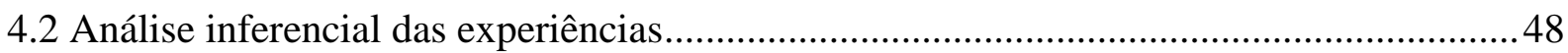

4.2.1 Relação entre modos e resultados de inovação ............................................................... 49

4.2.2 Relação entre capacidades e modos de inovação ……………………………………....50

4.2.3 Relação entre capacidades, modos e resultados .............................................................52

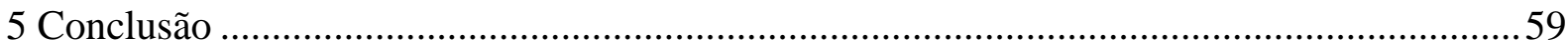

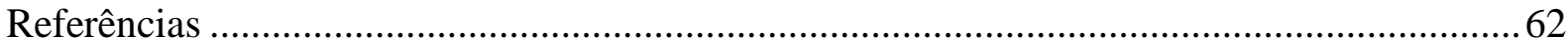

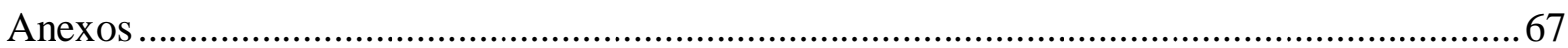

Anexo A - Protocolo de coleta e codificação de informações ...................................................... 67

Anexo B - Modelo de quadro para coleta e codificação de informações .................................. 70

Anexo C - Consulta efetuada sobre o modelo de inovação no Poder Executivo Federal.........71 


\section{Introdução}

A inovação que integra o sistema de produção é fundamental para o desenvolvimento econômico e também para entrega e efetividade dos serviços públicos. Pesquisas em inovação no passado estiveram concentradas no setor manufatureiro. Contudo, a partir da década de 1980, esse cenário foi superado devido à importância do setor de serviços nas economias desenvolvidas, devido a essa alteração de estrutura os pesquisadores organizacionais destinaram maior atenção ao processo inovativo (Tigre, 2006).

A organização econômica de diversos países têm migrado do setor industrial para o setor de serviços, pois as suas economias são complexas e estão baseadas principalmente nos serviços e no compartilhamento de conhecimento (Hauknes, 1998). O setor de serviços é abrangente e inclui várias atividades, desde o comércio de mercadorias, atividades financeiras, correios, telecomunicações, educação, saúde até a administração pública. Assim, o estudo da inovação em serviços pode favorecer o entendimento da inovação na indústria, pois o setor industrial executa diversas atividades de serviços (Kubota, 2009).

A inovação é uma área com grande potencial para ser explorada devido às suas especificidades e à sua complexidade. Pesquisadores como Djellal e Gallouj (2007) ressaltam a importância de estudar o processo de inovação em serviços para compreender o fenômeno em profundidade, sugerindo uma abordagem integradora para considerar bens e serviços de forma conjunta no processo de inovação.

As organizações públicas e privadas têm objetivos distintos, por isso apresentam processos de inovação em serviços com particularidades que dependem da sua área de atuação. No setor privado o lucro e a competição tornam as empresas mais eficientes e competitivas. Por outro lado, o setor público aparenta ser mais estático e homogêneo em relação ao setor privado, pois o lucro não é o objetivo principal desse setor, necessitando de um aprofundamento nas pesquisas para o melhor entendimento do processo de inovação e não há competição no setor público (Halvorsen, Hauknes, Miles, \& Roste, 2005).

A inovação no setor público é essencial para melhorar a eficiência e o aumento de desempenho na prestação de serviços (Albury, 2005). Inovação no setor público pode ser definida como a aplicação de uma nova forma de ação social implementada deliberadamente pela entidade. Assim, inovação é fazer algo de uma forma diferente e intencional para 
alcançar objetivos, posto que a sua motivação é desenhada de acordo com o ambiente do indivíduo ou entidade social (Koch \& Hauknes, 2005).

O setor público refere-se à coordenação, à produção e à entrega de bens e serviços pelas organizações públicas, pois envolvem a produção econômica incluindo a educação, saúde, assistência social e a prestação de serviços públicos (Potts \& Kastelle, 2010). Nessa perspectiva, a busca pela modernização é um fator importante para o estado conseguir uma maior eficiência e oferecer serviços com o mínimo de qualidade aos cidadãos.

A compreensão do caráter eminentemente interativo dos processos de inovação colocou no centro das discussões de políticas públicas a necessidade de empreender ações com vistas a ampliar e/ou melhorar as articulações entre os componentes principais dos sistemas de inovação e, com isso, potencializar as possibilidades de crescimento econômico e ampliar a efetividade dos serviços públicos (Carrijo \& Botelho, 2013). O sistema nacional de inovação é "uma construção institucional, produto de uma ação planejada e consciente ou de um somatório de decisões não-planejadas e desarticuladas, que impulsiona o progresso tecnológico em economias capitalistas complexas" (Albuquerque, 1996, p. 57).

O serviço público pode ser definido como: "toda atividade material que a lei atribui ao Estado para que exerça diretamente ou por meio de seus delegados, com o objetivo de satisfazer concretamente às necessidades coletivas, sob regime jurídico total ou parcialmente público" (Di Pietro, 2005, p.99). Desta feita, o setor público é uma área importante para o estudo de inovação.

A melhoria no gasto público é um fator importante para o Estado Brasileiro, pois governos devem ser mais eficientes e custarem menos para os cidadãos, para atingir esse objetivo a inovação é fundamental para que seja efetuada uma gestão mais eficiente de modo a potencializar os resultados, como por exemplo, a melhoria na entrega do serviço público e melhoria na gestão organizacional.

Uma das formas de incentivar as inovações no setor público é por meio de prêmios. No Brasil existem diversos prêmios de incentivo à inovação de abrangência nacional. Assim, no intuito de premiar e incentivar a inovação no setor público federal brasileiro, a Escola Nacional de Administração Pública - ENAP, desde 1996 em parceria com o Ministério do Planejamento, Orçamento e Gestão - MPOG, que é órgão central do Governo Federal quando se trata de traçar planejamentos e estratégias para o Poder Executivo Federal, vem recompensando as melhores iniciativas inovadoras por meio de um Concurso de Inovação. 
No setor público federal brasileiro não há um modelo definido de mensuração de inovação para ser utilizado por todas as organizações públicas. Por isso, existe a necessidade de se buscar os modelos de mensuração internacionais do setor público, para que se possa avançar nas pesquisas de inovação. Uma das vantagens dos modelos internacionais é que são modelos que foram testados em diversas organizações públicas em diferentes países. Outra vantagem é que os modelos de mensuração permitem verificar as relações entre os esforços de inovação e os resultados de inovação, sendo que as capacidades e modos de inovação são essenciais para que ocorra o resultado.

Com base nos modelos internacionais de mensuração da inovação obtêm-se as hipóteses para verificar o desempenho da inovação no setor público. As três variáveis selecionadas deste trabalho para verificar as hipóteses são: modos, capacidades e resultados de inovação. Os modos de inovação são definidos como aplicar ideias e conhecimento para gerar valor. Capacidade de inovação é uma série de processos que são projetados para gerar e aplicar ideias e conhecimentos para levar a novos e diferentes produtos, políticas, processos, tecnologias, empreendimentos e sistemas de negócios. O resultado de inovação é o impacto da inovação no desempenho da organização (InnovationUnit, 2009).

A etapa de elaboração de um banco de dados dos prêmios de inovação da ENAP, por meio de uma análise de conteúdo das experiências premiadas foi objeto de pesquisa do grupo NINE da Universidade de Brasília, que teve como resultado a construção do banco de dados denominado InnovaPublic, que contém a codificação dos diversos relatos da ENAP.

Assim, com os elementos disponíveis que são a metodologia e os dados, e no intuito de aumentar a efetividade e o alcance da inovação no setor público federal, este estudo desenvolve-se sobre a seguinte pergunta de pesquisa: qual é a relação entre capacidades, modos e resultados de inovação na Administração Pública Federal Brasileira?

\subsection{Objetivos}

Dessa maneira, com lastro nos modelos internacionais de mensuração e na relevância da inovação no setor público, esta pesquisa tem por objetivo verificar a relação entre capacidades, modos e resultados de inovação nas experiências inovadores em gestão na 
Administração Pública Federal, a partir da análise de experiências inovadoras premiadas pela Escola Nacional de Administração Pública - ENAP.

Para a consecução do objetivo geral, são propostos os seguintes objetivos específicos:

I. verificar nos relatos das experiências inovadoras a existência de capacidades, modos e resultados de inovação;

II. testar quais modos de inovação influenciam mais significativamente a ocorrência de resultados de inovação nas experiências selecionadas;

III. testar quais capacidades de inovação influenciam mais significativamente a ocorrência de modos de inovação nas experiências selecionadas;

IV. testar quais modos acrescidos de capacidades de inovação influenciam mais significativamente a ocorrência de resultados de inovação nas experiências selecionadas.

Ademais, como contribuição prática, este estudo engendrará um diagnóstico para os gestores públicos, pois na medida em que se identifica a relação entre capacidades, modos e resultados de inovação, isto pode melhorar a gestão, eficiência e eficácia da Administração. Como contribuição teórica pretende elaborar um modelo com base nos modelos internacionais de mensuração da inovação para subsidiar a construção de um modelo de mensuração de inovação brasileiro. A verificação dos modelos é importante, pois de acordo com Yen, Wang, Wei, Hsu e Chiu (2012) são poucos os estudos que têm testado modelos empiricamente em inovação em serviços.

Por fim, um trabalho científico precisa apresentar contribuições acadêmicas e práticas, visto que a administração é uma ciência essencialmente aplicada e nestas contribuições residem a justificativa e a relevância do trabalho. Assim, com uma análise descritiva e por meio de análise das experiências inovadoras na gestão pública, pretende-se verificar as relações citadas nos objetivos. Este esforço está alinhado com as iniciativas internacionais que buscam um modelo mais abrangente para inovação no setor público (Hughes, Moore, \& Kataria, 2011). 


\section{Referencial Teórico}

Os estudos em inovação cresceram rapidamente ao longo dos últimos anos do século XX (Djellal, Gallouj, \& Miles, 2013). Conforme os autores é frequentemente observado que a pesquisa tem sido dominada por um foco na indústria de transformação e, em particular, por indústrias de alta tecnologia, como a aeroespacial, a automotiva e os produtos farmacêuticos.

O cenário mundial contemporâneo atribui à inovação um papel fundamental no desenvolvimento econômico de um país, pois a cada dia cresce o número de empresas que veem na inovação uma oportunidade de elevar a sua competitividade e sobreviver em um mercado cada vez mais dinâmico e incerto (Kato, Gobara, Rossoni, \& Cunha, 2008).

A forte relação entre inovações e desenvolvimento econômico foi estabelecida em trabalhos realizados nas últimas décadas por parte de autores neoschumpeterianos e evolucionistas (Carrijo \& Botelho, 2013).

Higgins (1995) e Levitt (1990) explicam que a inovação consiste em um processo de criar algo novo com um valor significativo para um indivíduo ou uma coisa inteiramente nova, nunca feita antes, ou quando alguma coisa que foi feita em outro lugar sirva como inovação a outros pela primeira vez. Já para Tidd, Bessant e Pavitt (2008), a inovação é movida pela habilidade de estabelecer relações, detectar oportunidades e tirar proveito das mesmas.

Nesse contexto, Gallouj (2002) afirma que a inovação não é um resultado final e conclusivo (artefato), mas um processo de resolução de problemas, no qual a aprendizagem e interações múltiplas entre os agentes têm o papel principal. Segundo a teoria evolucionária, a inovação seria um processo de solução de problemas, dentro de um paradigma, o qual induziria soluções cumulativas, formando trajetórias de soluções, o que pode até cercear a capacidade de encontrar soluções fora dessas trajetórias (Nelson \& Winter, 2005).

O papel da inovação organizacional é ressaltado por Lam (2005) ao enfatizar que os economistas supõem que a inovação organizacional é uma resposta a uma mudança técnica, quando de fato a inovação organizacional poderia ser uma condição necessária para a inovação técnica. Para Fontenelle (2012), enquanto o debate em torno da mudança nos remetia a um momento específico de transformação organizacional, suportado por um projeto 
cuja implantação focava um resultado final, a inovação, ao contrário, é uma categoria que está no núcleo do processo produtivo e organizacional contemporâneo, remetendo à ideia de mudança como algo constante e permanente.

Segundo o Manual de Oslo, da Organização para Cooperação Econômica e Desenvolvimento (OCDE), cujo objetivo é orientar e padronizar diretrizes para coleta e interpretação de dados sobre inovação, são quatro os tipos de inovação: inovação de produto, que é a introdução de um bem ou serviço novo ou significativamente melhorado no que concerne a suas características ou usos previstos; inovação de processo, que é a implementação de um método de produção ou distribuição novo ou significativamente melhorado, incluindo mudanças significativas em técnicas, equipamentos e/ou softwares; inovação de marketing, que é a implementação de um novo método de marketing com mudanças significativas na concepção do produto ou em sua embalagem, no seu posicionamento, em sua promoção ou na fixação de preço; e inovação organizacional, que é a implementação de um novo método organizacional nas práticas de negócios da empresa, na organização do seu local de trabalho ou em suas relações externas (OECD, 2005).

Com o objetivo de reconhecer a importância da inovação para o desenvolvimento econômico e a necessidade de atuação política com vistas a aprimorar o sistema de inovações do Brasil, foi estabelecido um conjunto de políticas e leis (Carrijo \& Botelho, 2013). As autoras destacam que esses principais marcos regulatórios estão na Política Industrial, Tecnológica e de Comércio Exterior (PITCE), instituída em 2003; na Lei da Inovação (2004); na Lei do Bem (2005); no Programa de Crescimento Acelerado em CT\&I (PAC da Ciência, 2007); na Política de Desenvolvimento Produtivo (2008); e no Programa Brasil Maior (2011). Leite (2013) indica que o Brasil incentiva a inovação, majoritariamente, por meio de políticas públicas de financiamento à geração de inovação.

$\mathrm{Na}$ inovação, o Estado deve não somente corrigir falhas de mercado (por exemplo, por meio do financiamento para pesquisa básica e projetos de infraestrutura), mas também abrir espaço para o investimento privado dinamizando-o, cabendo ao Estado sinalizar para a sociedade sua visão, definir sua missão e formular e executar um planejamento coerente(Costa, Mendonça, \& Campos, 2015). No tópico a seguir será apresentado o tema da inovação no setor público objeto de pesquisa deste trabalho. 


\subsection{Inovação no setor público}

A inovação no setor público é essencial para melhorar a eficiência e a qualidade na prestação de serviços (Albury, 2005). Inovação no setor público pode ser definida como a aplicação de uma nova forma de ação social implementada deliberadamente pela entidade pública. Assim, inovação é fazer algo de uma forma diferente e intencional para alcançar objetivos, pois a sua motivação é desenhada de acordo com o ambiente do indivíduo ou entidade social (Koch \& Hauknes, 2005).

Uma das medidas de eficiência que serve como parâmetro para o mercado privado é o lucro, haja vista que a competição torna o setor privado mais dinâmico e serve como aperfeiçoamento para as empresas. Contudo, o setor público aparenta ser mais estático e homogêneo em relação ao setor privado (Halvorsen et al., 2005), não sendo o objetivo principal auferir lucro no setor público.

O setor público brasileiro pode auferir lucro atuando no setor privado por meio de empresas estatais. Essas empresas são criadas por meio de lei de duas formas: empresas públicas ou sociedades de economia mista, que desempenham atividade de natureza econômica, elas possuem personalidade jurídica de direito privado e estão sujeitas ao controle estatal (Di Pietro, 2005). Mesmo auferindo lucro, as referidas empresas têm como objetivo servir o Estado tendo como consequência servir ao povo.

O foco do setor público é o bem-estar dos seus cidadãos, sendo responsável pela aplicação dos impostos em saúde, educação, transporte e em outros bens e serviços. O Estado Brasileiro é burocrático e isto pode torná-lo lento e inflexível, a rigidez institucional representa uma barreira ao desenvolvimento, por exemplo, as universidades são dotadas de autonomia e gestão, mas precisam de aprovação do Legislativo para aumentar o quadro de professores, essa demora na decisão pode afetar a eficiência do setor público. (Salerno \& Kubota, 2008).

No que se refere às pesquisas em inovação no setor público existo o mito: "o setor público é menos inovador que o privado". No entanto, este mito não encontra lastro na realidade. Pode-se citar, por exemplo, o caso da universidade aberta, na Inglaterra, que proporcionou um maior alcance da educação para todas as pessoas, sendo uma medida inovadora que proporcionou uma maior eficiência do setor público (Albury, 2005). 
Nos trabalhos desenvolvidos no campo na inovação, autores como Eggers e Singh (2009) identificaram quatro etapas para o ciclo de inovação: a) geração de ideias e descobrimento; b) seleção de ideias; c) implementação de ideias e d) difusão de ideias.

A geração de ideias exige um compartilhamento de ideias e de metas observando o que outros órgãos ou organizações estão fazendo, conectando-se com os cidadãos para buscar informações sobre o atendimento e se as expectativas deles estão sendo satisfeitas.

A seleção de ideias envolve o processo de escolha das melhores ideias, esta é uma parte importante, pois as organizações públicas devem sustentar a escolha de modo a não ser impedida pelos diversos stakeholders, uma vez que eles podem possuir interesses conflitantes e grande poder de influência para inviabilizar as ideias.

A implementação de ideias é a etapa que após a seleção busca o refinamento e a execução das ideias. As boas ideias necessitam da conversão em programas, sob pena de caírem no esquecimento e de acabarem com a fonte de inspiração. Os fatores chaves para implementação das ideias são: atribuir a funcionários e parceiros uma parte do resultado, criar mecanismos de feedback, assegurar a comunicação na organização como um todo, incorporação de boas ideias no planejamento estratégico em nível gerencial e definir uma missão clara para o projeto ser avaliado.

A difusão é o último estágio do processo, que tem como objetivo distribuir a inovação por toda a organização e outras partes interessadas. São diversos métodos utilizados para difundir a inovação, por exemplo, redes de transferência de conhecimento, que procuram reunir diversos profissionais de inúmeras áreas para gerar inovações, facilitar o intercâmbio de conhecimento e informar o governo sobre normas que podem afetar o processo inovativo.

Os prêmios de inovação são uma importante prática para reunir as experiências e aproveitar a criatividade das pessoas, que não estão diretamente ligadas as atividades burocráticas do serviço público (Mulgan, 2014). O setor público premia as práticas inovadoras por meio de concursos de inovação. Dentre esses concursos destacam-se o concurso da Enap, Inovare e Concurso da RFB. O concurso da Enap e o Concurso da RFB são ligados ao Poder Executivo Federal, enquanto que o concurso Inovare está ligado ao Poder Judiciário.

\section{O Concurso Inovação na Gestão Pública Federal:}

É promovido anualmente, desde 1996, pela Escola Nacional de Administração Pública (Enap), em parceria com o Ministério do Planejamento, Orçamento e Gestão. A premiação valoriza as equipes de servidores públicos que, comprometidos com o alcance de melhores resultados, dedicam-se a repensar atividades cotidianas por meio de pequenas ou grandes inovações que gerem melhoria na gestão das organizações e políticas públicas, contribuam 
para o aumento da qualidade dos serviços prestados à população e tornem mais eficientes as respostas do Estado diante das demandas da sociedade (Enap, 2016, p.1).

O concurso funciona em avaliação do Comitê julgador que em análise preliminar seleciona até 20 iniciativas mais bem avaliadas que passam para a próxima fase. Nessa fase as 20 iniciativas selecionadas recebem a visita de uma dupla de integrantes do Comitê Técnico. $\mathrm{Na}$ visita in loco o Comitê Técnico tem a missão de averiguar e aprofundar as informações constantes do relato, assim como esclarecer dúvidas dos membros do Comitê Julgador. Na fase seguinte os integrantes do Comitê Julgador analisam os relatórios das visitas técnicas. Na ultima etapa o Comitê Julgador, com a participação do Comitê Técnico, a fim de aprofundar o conhecimento sobre as iniciativas e embasar a escolha e a classificação das dez inovações premiadas (Enap, 2016). A partir da $21^{\mathrm{a}}$ edição foi incluída a participação do Poder Executivo Estadual/Distrital no prêmio.

O Prêmio Innovare tem como objetivo identificar, divulgar e difundir práticas que contribuam para o aprimoramento da Justiça no Brasil, sendo sua comissão composta por inúmeros juristas, inclusive representantes dos tribunais superiores. O Conselho Superior é composto por associações representativas do Poder Judiciário, Ministério Público, Ordem dos Advogados do Brasil. O total de práticas submetidas ao concurso é superior a 5.000 (cinco mil) e são oriundas de todos os estados do país. O número indica um esforço por parte dos intervenientes do Poder Judiciário na tentativa de criar valor para os cidadãos. (Innovare, 2016).

Prêmio criatividade e inovação da Receita Federal do Brasil - RFB foi criado em 2002, sendo inserido numa política de valorização e reconhecimento dos servidores da RFB. A partir de 2010 o prêmio foi estendido aos servidores e empregados do Ministério da Fazenda. O objetivo do concurso é reconhecer e valorizar os trabalhos de qualidade técnica e aplicabilidade na implantação de boas práticas de gestão e melhoria dos processos de trabalhos e serviços prestados ao contribuinte. Os trabalhos são apresentados no formato de monografia com o seguinte tema: "implantação de Boas Práticas de Gestão e Melhoria dos Processos de Trabalho", conforme determina o artigo $5^{\circ}$ da Portaria RFB n ${ }^{\circ}$ 1015, de 13 de Maio de 2014. (Esaf, 2016).

Os três prêmios apresentam abrangência nacional, porém o prêmio da Receita Federal está restrito aos servidores e empregados do Ministério da Fazenda, enquanto que o da Enap está restrito aos servidores do Poder Executivo Federal, e o Innovare está ligado ao Poder Judiciário e os seus intervenientes. Contudo, não há uma uniformização dos critérios e dos 
objetivos dos prêmios de inovação do setor público, não é apresentado um arcabouço teórico comum, o que poderia permitir uma comparação mais eficiente entre as diversas organizações e um caminho a ser seguido por elas.

Um modelo comum de mensuração da inovação para o serviço público brasileiro representaria um esforço sistemático para gerir o processo de inovação, o que traria uma melhor gestão para os processos inovadores na administração pública. O próximo tópico apresenta alguns modelos de inovação internacionais que ilustram o esforço de sistematização do processo de inovação efetuado por outros países.

\subsection{Modelos de inovação no setor público}

Primeiro, cabe ressaltar que não existe um modelo de inovação do setor público brasileiro, conforme informação do órgão central do Poder Executivo Federal, que é o Ministério do Planejamento, Desenvolvimento e Gestão (anexo C). O órgão informou que vem empenhando esforços no sentido de incentivar e estruturar a inovação no setor público por meio de atuação cooperativa e em rede. Informou sobre a criação da InovaGov que é uma rede de pessoas e organizações que busca estimular e integrar a inovação no setor público criada em 2016. Por fim, noticiou o blog http://redeinovagov.blogspot.com.br/?.

O governo brasileiro usa blog gratuito que foi criado em 2016 para servir como um intercâmbio de experiências entre organizações e pessoas de modo a incentivar a inovação no setor público. Das três informações (ausência de modelo, blog gratuito e criação em 2016) evidencia-se que a sistematização da inovação no setor público brasileiro ainda está iniciando, por isso existe uma lacuna que precisa ser preenchida por meio de modelos e pesquisas internacionais para avaliação da inovação no setor público brasileiro.

Os modelos internacionais de mensuração de inovação voltados para o setor público apresentam as influências entre as variáveis de inovação: capacidade, atividade, barreiras, indutores e resultados/desempenho. Nesta seara, destacam-se três modelos de mensuração do setor púlico que são: a) Innovation Unit; b) NESTA e c) APSII. O innovation Union e o NESTA (National Endowement for Science Technology and the Arts) são do Reino Unido, enquando que o APSII (Australian Public Sector Innovation Indicators Project) é australiano. 


\section{a)Innovation Unit}

O modelo proposto pelo Innovation Unit é resultado de um projeto exploratório, que foi testado em uma escola de ensino fundamental, outra de ensino médio e a secretaria de educação. O objetivo do projeto era desenvolver os indicies de inovação para o setor público

A representação gráfica do modelo pode ser observada na Figura 1 e é composta pela união de três conjuntos de círculos, cada conjunto recebe o nome de domínio. Desta forma, os três domínios são: a) capacidade de inovação; b) Atividade de Inovação e c) Resultado de inovação. A Figura 1 apresenta o modelo

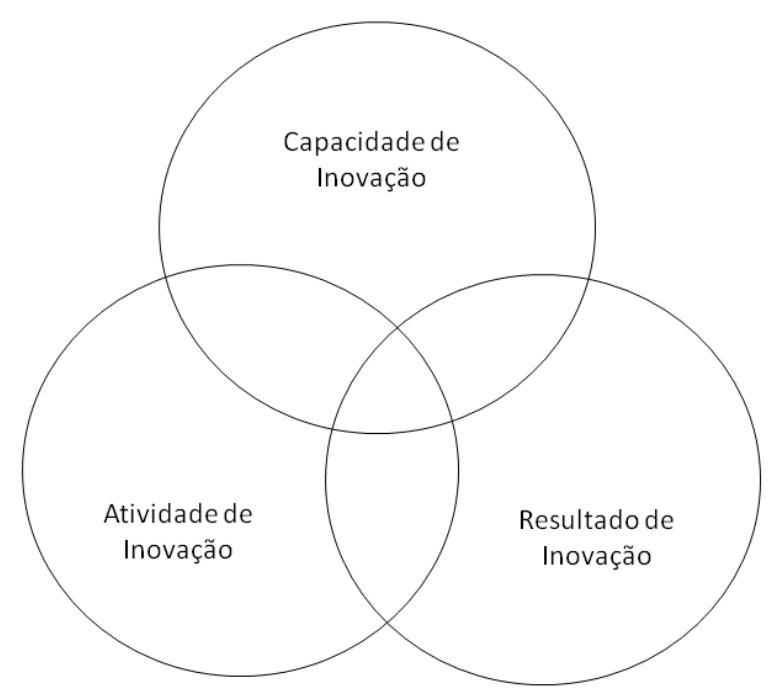

Figura 1 - Modelo de inovação Innovation Unit

Fonte: Adaptado de InnovationUnit, (2009, p.8)

Nesse contexto, atividades de inovação são definidas como aplicar ideias e conhecimento para gerar valor. Capacidade de inovação é uma série de processos que são projetados para gerar e aplicar ideias e conhecimentos para levar a novos e diferentes produtos, políticas, processos, tecnologias, empreendimentos e sistemas de negócios. $\mathrm{O}$ resultado de inovação é o impacto da inovação no desempenho da organização, porém existem várias ressalvas em relação à mensuração do resultado, pois medir o desempenho não 
é simples devido a inúmeros fatores. Exemplos da dificuldade de mensuração do resultado de inovação: (i) as organizações podem aumentar o desempenho sem inovar; (ii) podem diminuir o desempenho inovando, pois a mão de obra ainda não está adaptada; (iii) a inovação pode ser bem sucedida e demorar anos para surgir um melhor desempenho; (iv) a inovação pode criar valor para os usuários, contudo a organização não consegue capturar o valor para a organização.

O modelo indica que as relações entre capacidade de inovação são importantes para realização de atividades de inovação, quando a relação entre esses domínios é benéfica pode conduzir para os resultados de inovação. Todavia, essa relação entre os domínios não é expressa no modelo gráfico da Figura 1.

b) National Endowement for Science Technology and the Arts - NESTA

O modelo do NESTA também apresenta áreas de avaliação da inovação como o modelo da Innovation Unit com acréscimo de um item no modelo. São quatro áreas de avaliação: a) atividade de inovação; b) capacidade de inovação; c) impacto no desempenho e d) condições setoriais para inovação. A Figura 2 representa o modelo NESTA.

As áreas incluindo as atividades de inovação, capacidade de inovação e impacto no desempenho estão dentro do controle da organização. Em relação a área externa que representa as condições setoriais para inovação elas estão fora do controle da organização, mas estão no controle dos agentes políticos.

Uma das vantagens do modelo é que ele indica as relações entre os seus componentes que estão sob o controle da organização pública, que são as seguintes:

a) atividades de inovação pode influenciar o desempenho;

b) capacidade de inovação pode influenciar atividades de inovação;

c) capacidades de inovação acrescidas de atividades de inovação podem influenciar o desempenho. 


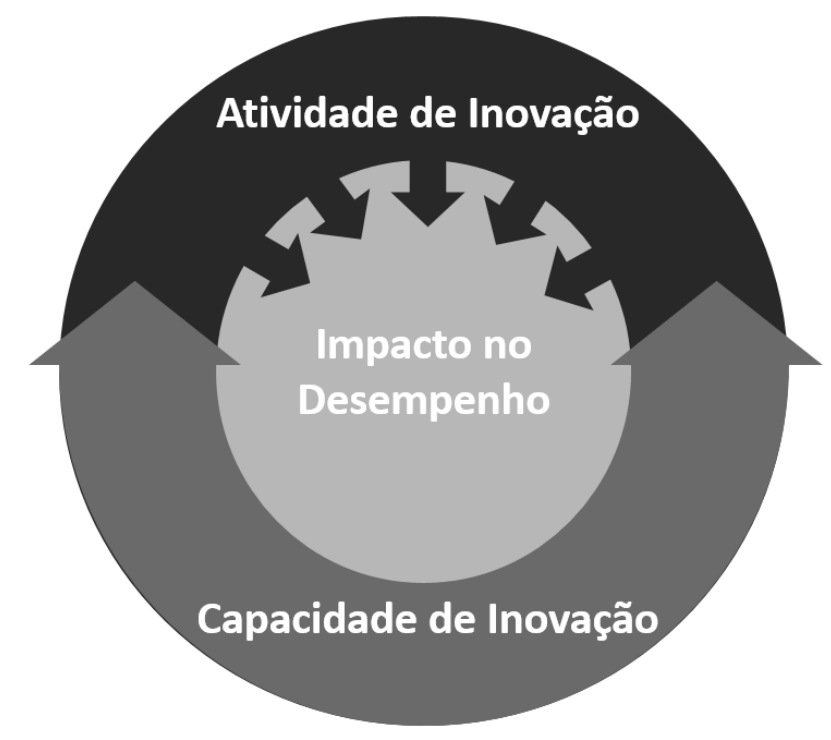

Condições Setoriais para Inovação

Figura 2 - Modelo de inovação NESTA

Fonte: Adaptado de Hughes et al. (2011, p. 47)

Em relação aos itens do modelo, a capacidade de inovação pode ser subdividida em três aspectos: (i) liderança e cultura, este item está associado às condições necessárias e comportamentos para que a inovação surja na organização pública, por exemplo, visão e espírito dos gestores, priorização da inovação, atitudes para assumir riscos e aprender; (ii) gestão da inovação, está ligado à qualidade da organização e ao planejamento de atividades de inovação, como por exemplo, governança da inovação, engajamento profissional e gestão de riscos e (iii) facilitadores organizacionais da inovação, representa o que pode ser facilitado para atividade de inovação, por exemplo, informações gerenciais, fóruns e eventos, incentivos e recompensas.

Atividades de inovação são identificadas como condutores, a metáfora é que funcionariam como um funil para as novas ideias, isto permitiria identificar, selecionar, desenvolver, implementar e difundir as melhores ideias. As atividades podem ser subdivididas nos seguintes aspectos: (i) acessando novas ideias, que representa o processo de acessar e identificar um número suficiente de diferentes tipos de ideias a partir de várias fontes, como por exemplo, cidadãos, colaboradores, fornecedores, gestores; (ii) selecionando e desenvolvendo ideias, esta etapa busca selecionar as melhores ideias novas para desenvolvimento, também busca alocar recursos financeiros e técnicos, selecionar uma equipe 
multidisciplinar e elaborar um teste piloto; (iii) implementado ideias, esta fase representa o processo de conversão das ideias testadas para soluções totalmente implementadas, nesta fase procura-se a incorporação e o dimensionamento, treinamento, mensuração de benefícios incluindo os intangíveis; (iv) difusão das inovações exitosas, significa que a ideia deve ser compartilhada e disseminada dentro e fora da organização.

O desempenho fornece uma visão para os gestores sobre o impacto da inovação no desempenho da organização está segmentada em: (i) melhoria dos principais indicadores de desempenho organizacional; (ii) melhoria na avaliação dos serviços; (iii) melhoria na eficiência; (iv) melhoria no clima organizacional. Esta fase busca avaliar os dados recentes sobre a melhoria dos resultados organizacionais.

\section{c) Australian Public Sector Innovation Indicators Project - APSII}

O modelo segue na mesma direção dos outros dois apresentados, mostrando capacidade de inovação influenciando o desempenho de inovação, o modelo acrescenta dois componentes que são indutores e barreiras de inovação, conforme Figura 3.

Desta forma, o modelo apresenta quatro componentes principais: a) capacidade de inovação; b) desempenho de inovação; c) indutores de inovação e d) barreira para inovação. O modelo apresenta setas que indicam a relação entre os componentes. As barreiras para inovação afetam negativamente a capacidade de inovação e o desempenho da inovação, enquanto que os indutores afetam positivamente os mesmos itens. 


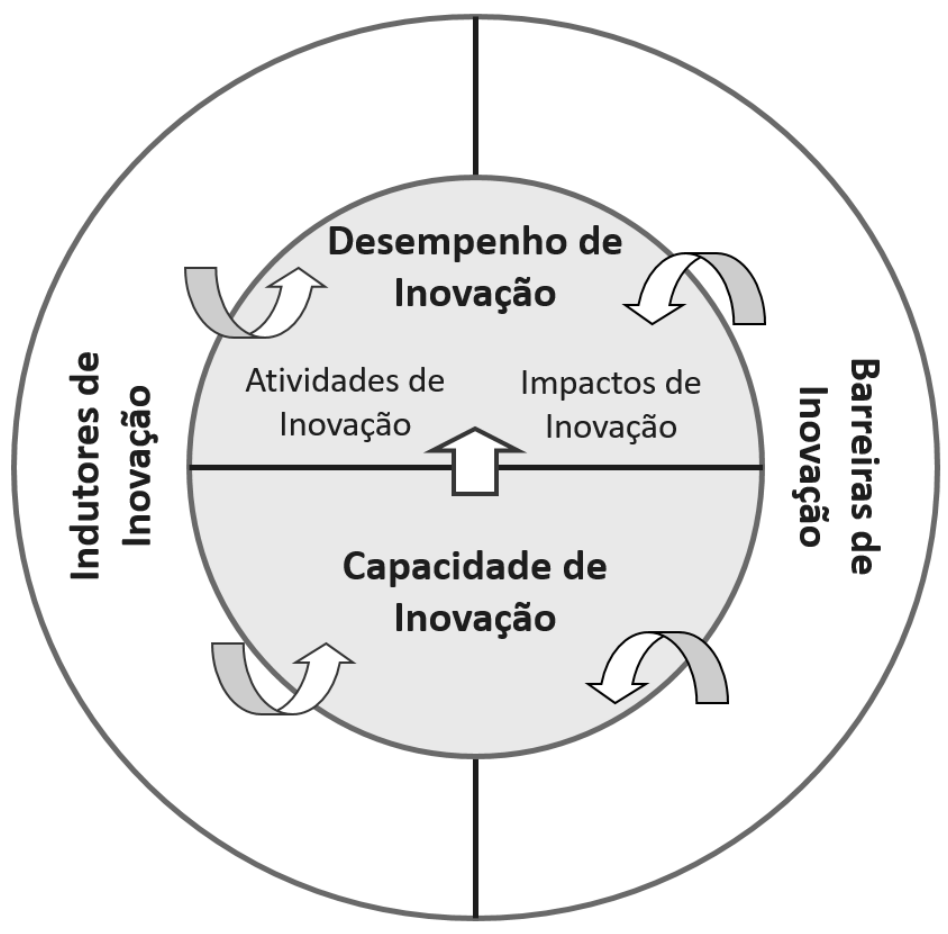

Figura 3 - Modelo de inovação APSII

Fonte: Adaptado de APSII (2011, p. 24)

A capacidade de inovação, atividades de inovação e desempenho de inovação tem conceitos similares aos apresentados nos modelos anteriores. Os indutores ou barreiras de inovação podem ser classificados em internos ou externos, sendo que indutores facilitariam o processo de inovação e barreiras dificultariam o processo de inovação. Os indutores poderiam influenciar positivamente tanto capacidade de inovação, quanto o desempenho de inovação, enquanto que as barreiras influenciariam esses mesmos componentes de maneira negativa.

A pesquisa para elaborar o modelo australiano foi efetuada em duas etapas sendo a primeira com agências públicas e a segunda com os empregados/servidores públicos. As agências públicas selecionadas tinham em seu quadro funcional mais de 20 empregados e foram aproximadamente 100 (cem) agências participantes. Quanto aos empregados/servidores públicos a pesquisa selecionou a partir do banco de dados do serviço público de emprego, a amostra tinha aproximadamente 9.000 (nove mil) funcionários.

d) Outros modelos

Os modelos supracitados são adotados por países, também existem outros modelos propostos por autores que seguem a mesma linha dos modelos anteriormente apresentados. $\mathrm{Na}$ revisão sistemática da literatura de inovação no setor público De Vries, Bekkers e Tummers 
(2016) constataram que os estudos envolvendo métodos mistos foram pouco comuns, e que falta uma base teórica clara nos estudos revisados. A figura 4 apresenta o modelo heurístico com base nos artigos que os referidos autores investigaram, sendo que o modelo deve ser interpretado como um guia, pois os componentes da estrutura não apresentam uma lista abrangente das inovações do setor público.

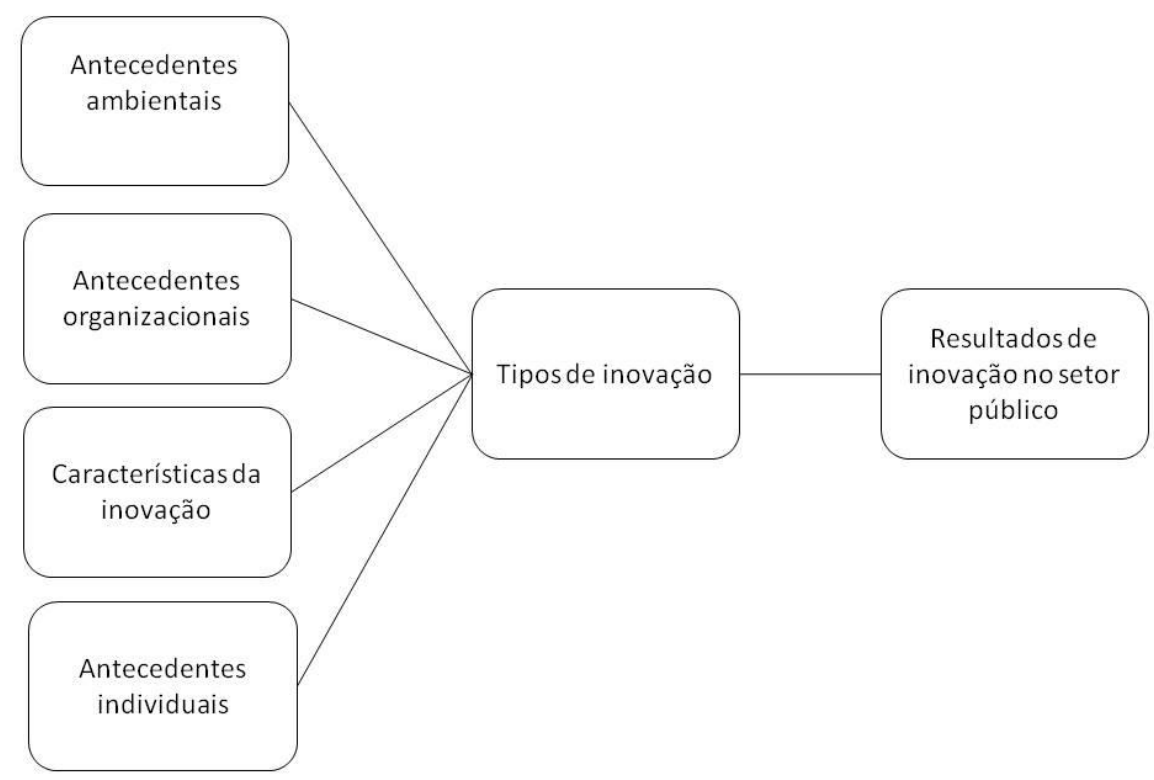

Figura 4 - Modelo heurístico de inovação do setor público Fonte: Adaptado de De Vries et al. (2016,p.162)

Os quatro componentes do modelo que predizem o tipo de inovação são: a) antecedentes ambientais, que se referem às pressões ambientais, aspectos regulatórios; b) os antecedentes organizacionais estão associados à falta de recursos, estilos de liderança, grau de aversão ao risco, local para aprendizagem, incentivos e recompensas, conflitos e estruturas organizacionais; c) características da inovação, se refere a facilidade no uso da inovação, vantagem relativa e compatibilidade; d) antecedentes individuais estão ligados à autonomia dos funcionários, posição organizacional, conhecimentos e competências profissionais, criatividade, aspectos demográficos, aceitação da inovação.

Os tipos de inovação estão relacionados com inovação de processos, inovação de processos administrativos, inovação de processos tecnológicos, inovação de produtos e serviços, governança da inovação e inovação conceitual. Os resultados de inovação estão associados com maior ou menor eficácia, maior eficiência, cidadãos envolvidos e maior satisfação dos clientes. Ao final os autores sugerem pesquisas envolvendo diversos países e setores, sendo possível utilizando múltiplos métodos de pesquisa. 
Alguns itens são comuns em todos os sistemas de inovação, outros itens estão implícitos em um sistema e explícitos nos outros. No que tange as barreiras e facilitadores da inovação eles são importantes fatores para a implementação dos processos, os facilitadores podem ser pessoas, organizações ou outros fatores que impulsionam o setor público a inovar, por exemplo, novas prioridades políticas, mudanças no orçamento, reclamações de usuários, influência de associações. As barreiras também afetam as inovações, por exemplo, a cultura da organização, fatores políticos, falta de flexibilidade nos normativos, falta de incentivo, falta de cooperação, resistência dos usuários as mudanças e tempo inadequado. (Bloch, 2011).

Os modelos de mensuração da inovação apresentados indicam o esforço de vários países e autores na obtenção de um arcabouço teórico para inovação no setor público. Os desafios que o setor público enfrenta são comuns nos diversos territórios, como por exemplo, redução de gastos por parte do governo, pressões ambientais, mudanças demográficas, inclusão social, saúde e educação acessíveis, globalização.

Nos próximos tópicos serão explicadas e delimitadas as variáveis de interesse desta pesquisa, que são capacidade de inovação, modos de inovação e resultados de inovação.

\subsection{Capacidades e modos de inovação}

A capacidade de inovação é oriunda das habilidades e aptidões que permitem a alocação de recursos, e representa um processo continuo de transferência de conhecimento em novos produtos, processos e sistemas para benefício da organização e de seus intervenientes (Lawson \& Samson, 2001).

Para Koc (2007) a capacidade de inovação representa uma melhoria contínua nos recursos gerais de uma organização, para explorar oportunidades de desenvolvimento de novos produtos.

O modelo de capacidade de inovação utilizado neste trabalho é o resultado do trabalho desenvolvido por Valladares, Vasconcellos, \& Serio (2014), que perceberam a lacuna existente na literatura e identificaram os principais fatores determinantes e fator resultante da capacidade de inovação que permitiram a construção de escalas de medição para pesquisas empíricas. 
No trabalho de Valladares, Vasconcellos e Serio (2014) a definição sobre capacidade de inovação foi à mesma de Peng, Schroeder e Shah (2008) em que "capacidade de inovação é força ou a proficiência de um conjunto de práticas organizacionais para o desenvolvimento de novos produtos/processos" (p. 735).

O esforço para obtenção da tipologia contida no Quadro 1 apresenta a síntese dos fatores determinantes e resultantes da capacidade de inovação e os seus domínios teóricos. A abordagem tem $\mathrm{o}$ foco em capacidades que podem ser expressas em processos organizacionais, desta forma, certas capacidades como cultura, aprendizagem organizacional, recursos não foram incluídas como fator isolado.

\begin{tabular}{|l|l|}
\hline \multicolumn{1}{|c|}{ Capacidade } & \multicolumn{1}{c|}{ Definição } \\
\hline $\begin{array}{l}\text { Liderança } \\
\text { transformadora }\end{array}$ & $\begin{array}{l}\text { Aquela que torna seus seguidores mais conscientes da importância e do valor do trabalho; } \\
\text { ativa suas necessidades de ordem superior; e os induz a transcender seus interesses } \\
\text { pessoais em prol da organização. }\end{array}$ \\
\hline $\begin{array}{l}\text { Intenção } \\
\text { estratégica } \\
\text { inovar }\end{array}$ & $\begin{array}{l}\text { Grau que a empresa está disposta a assumir riscos para favorecer a mudança, o } \\
\text { desenvolvimento tecnológico e a inovação, e a competir agressivamente a fim de obter } \\
\text { uma vantagem competitiva para sua empresa. }\end{array}$ \\
\hline $\begin{array}{l}\text { Gestão de pessoas } \\
\text { para inovação }\end{array}$ & $\begin{array}{l}\text { Orientação da gestão de pessoas para a inovação, provendo a concessão de liberdade ou } \\
\text { autonomia de atuação aos empregados, estabelecendo metas desafiadoras, permitindo que } \\
\text { decidam como alcançá-las e favorecendo a autorrealização e o comprometimento com os } \\
\text { objetivos da organização }\end{array}$ \\
\hline $\begin{array}{l}\text { Conhecimento do } \\
\text { cliente e } \\
\text { mercado }\end{array}$ & $\begin{array}{l}\text { Habilidade para detectar os eventos, necessidades, expectativas, mudanças significativas } \\
\text { e tendências do cliente e do mercado. Perceber as mudanças do mercado na frente dos } \\
\text { seus competidores fornece vantagem competitiva à empresa }\end{array}$ \\
\hline $\begin{array}{l}\text { Gestão estratégica } \\
\text { da tecnologia }\end{array}$ & $\begin{array}{l}\text { Gestão do processo de criação e desenvolvimento de tecnologias, visando à criação de } \\
\text { valor. O processo de gestão tecnológica compreende cinco etapas: identificação, seleção, } \\
\text { aquisição, explotação e proteção }\end{array}$ \\
\hline $\begin{array}{l}\text { Organicidade } \\
\text { estrutura } \\
\text { organizacional }\end{array}$ & $\begin{array}{l}\text { Grau em que a estrutura é caracterizada pela concessão de autonomia, controles flexíveis, } \\
\text { comunicação horizontal desimpedida, valorização do conhecimento e da experiência e } \\
\text { informalidade nas relações pessoais. Estruturas ditas orgânicas permitem resposta mais } \\
\text { rápida às mudanças no ambiente externo do que as denominadas mecanicistas. }\end{array}$ \\
\hline $\begin{array}{l}\text { Gestão de projetos } \\
\text { Planejamento, provisão dos recursos, execução e controle do processo de inovação. } \\
\text { Inclui cuidadosa avaliação dos projetos, análise e planejamento visando, principalmente, } \\
\text { ganhar compreensão, compromisso e apoio tanto corporativo quanto do pessoal que } \\
\text { estará envolvido no projeto. }\end{array}$ \\
\hline
\end{tabular}

Quadro 1 - Capacidades de inovação.

Fonte: Adaptado de Valladares et al. (2014).

Em relação aos modos de inovação será adotada a abordagem integradora, que resultou de esforços teóricos propostos por Gallouj e Savona (2009), que identificaram três abordagens principais voltadas a este tema, que são: a) tecnicista ou de assimilação; b) baseada em serviços ou de diferenciação e c) integradora ou de síntese. 
A primeira abordagem é a de assimilação ou tecnicista é a mais antiga (Gallouj, 2002) e estuda a introdução de sistemas tecnológicos em organizações de serviços e indústrias e aborda o uso de tecnologias para inovação em serviços. É uma perspectiva que abrange originalmente estudos desenvolvidos para a dinâmica do setor industrial deslocada para análise de serviços. A principal crítica é que essa abordagem reduz a inovação em serviços à adoção ou utilização de tecnologias e a contribuição dos estudos dessa perspectiva foca na tentativa de assimilar os serviços aos modelos consolidados da indústria, desconsiderando outros aspectos da inovação em serviços. (Gallouj \& Savona, 2009).

A segunda abordagem é a baseada em serviços ou de diferenciação que tem como objetivo ressaltar que mais importante que as inovações tecnológicas são as inovações produzidas entre o cliente e o fornecedor de serviços, ou seja, o intuito é destacar as especificidades da inovação em serviços, como características intrínsecas aos serviços, por exemplo, imaterialidade, interatividade e coprodução, transformando o modelo de caracterização tradicional (abordagem de assimilação) obsoleto. $\mathrm{O}$ conceito principal dessa teoria está na relação usuário-provedor, que, de acordo com Hauknes (1998), apesar das variações em seu grau de intensidade conforme o ramo, contribui para a inovação no desenvolvimento do serviço, incluindo produção e processo, superando qualquer inovação tecnológica de processo ou de produto. Na realidade trata-se de um modelo teórico que surge como resposta à abordagem tecnicista, ou seja, é um modelo de oposição que considera a abordagem tecnicista reducionista. A crítica a essa abordagem é que ela não permite uma comparação com os setores industriais, pois operacionaliza a compreensão somente da dinâmica da inovação em serviços.

A terceira abordagem é a integradora que propõe unir a teoria para bens e serviços. É uma teoria que permite realizar análises de forma indistinta, pois busca uma convergência entre os setores industriais e os setores de serviços, entre produtos tangíveis e intangíveis, na mesma estrutura conceitual. É a perspectiva base para a classificação da inovação deste trabalho, que visa conceber abordagens gerais para a inovação, independentemente da divisão entre bens e serviços (Hauknes, 1998). A ideia geral é que a inovação envolve características genéricas, e a importância dessas características está atrelada à intensidade da interação entre usuário-produtor do mercado em análise. Hauknes (1998) defende que existe um processo de convergência ao longo de um continuum entre as indústrias de manufatura e serviços. Assim, o "produto" pode ser um bem ou um serviço. 
Desta forma, o modelo que integra bens e serviços proposto por Gallouj (2002) contempla em uma análise única os bens e serviços. O modelo contido na figura 1 foi criado a partir da definição de (Hill, 1977) e (Gadrey, Gallouj, \& Weinstein, 1995) e da descrição de produto de Saviotti \& Metcalfe (1984) e integra as abordagens de produto e serviço em um único modelo de inovação. Assim, os quatro vetores [C, C', X e Y] representam componentes de produtos de serviços, sendo que o vetor [C] representa as competências diretas dos fornecedores, o vetor [C'] representa a competência dos clientes, o vetor [Y] representa as características finais ou de serviços, que correspondem ao serviço ou produto final e o vetor $[\mathrm{X}]$ representa as características técnicas materiais ou imateriais.

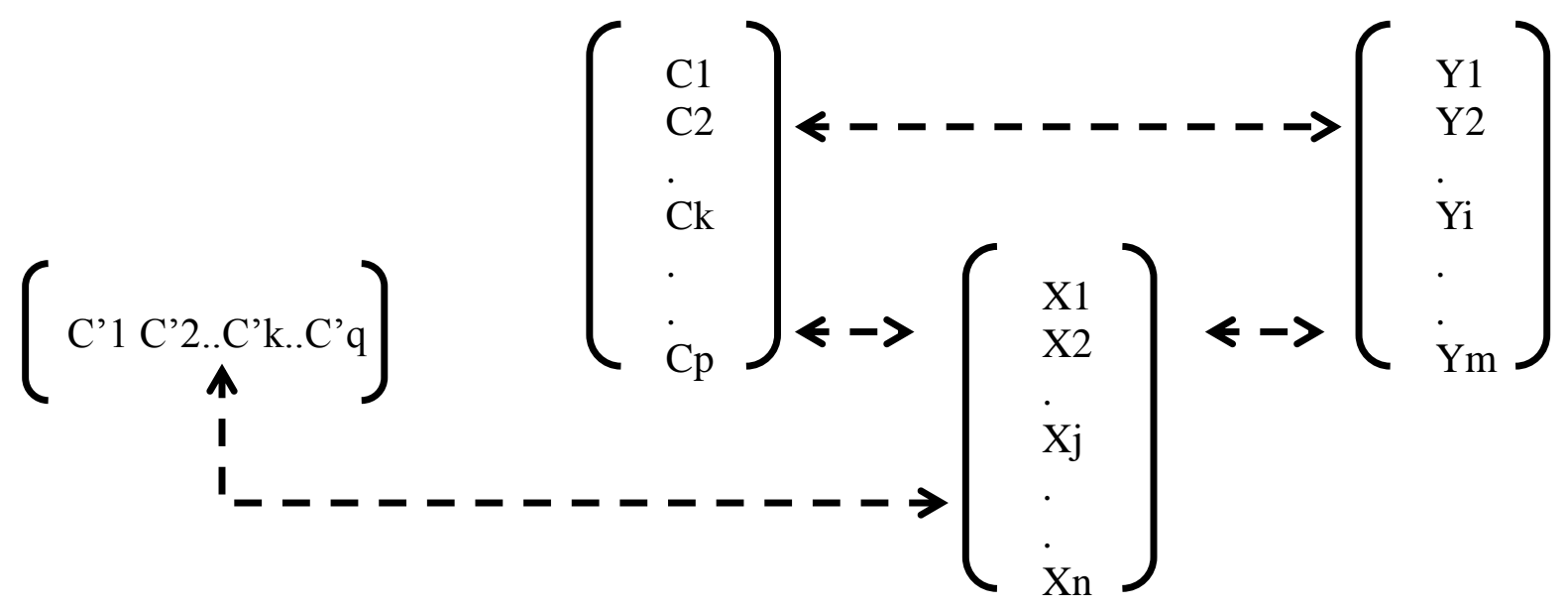

Figura 5 - A forma mais geral do produto como um sistema de características e competências

Fonte: Adaptada de Gallouj (2002). Innovation in the service economy: the wealth of nations. (p.58). Cheltenham: Edward Elgar.

A inovação, segundo Gallouj (2002) seria representada nesse modelo (Figura 1) como alguma mudança que afeta um ou mais termos, de um ou mais vetores, das características ou de competências no sistema dos vetores $\left[\mathrm{C}, \mathrm{C}^{\prime}, \mathrm{Y}\right.$ e $\left.\mathrm{X}\right]$ para gerar valor. Essas alterações são provocadas por uma gama de fatores, por exemplo, surgimento, desaparecimento, variação, associação, dissociação nos vetores.

O modelo foi expandido para adotar diferentes casos complexos de inovação em serviços, como por exemplo, serviços em rede ou serviços públicos onde o governo está envolvido na inovação (Gallouj \& Savona, 2010), sendo que as características dos serviços foram divididas em internas e externas. Desta forma, o modelo ficou com cinco vetores $[\mathrm{C}$, C', Y, T'e T], conforme figura 2. 


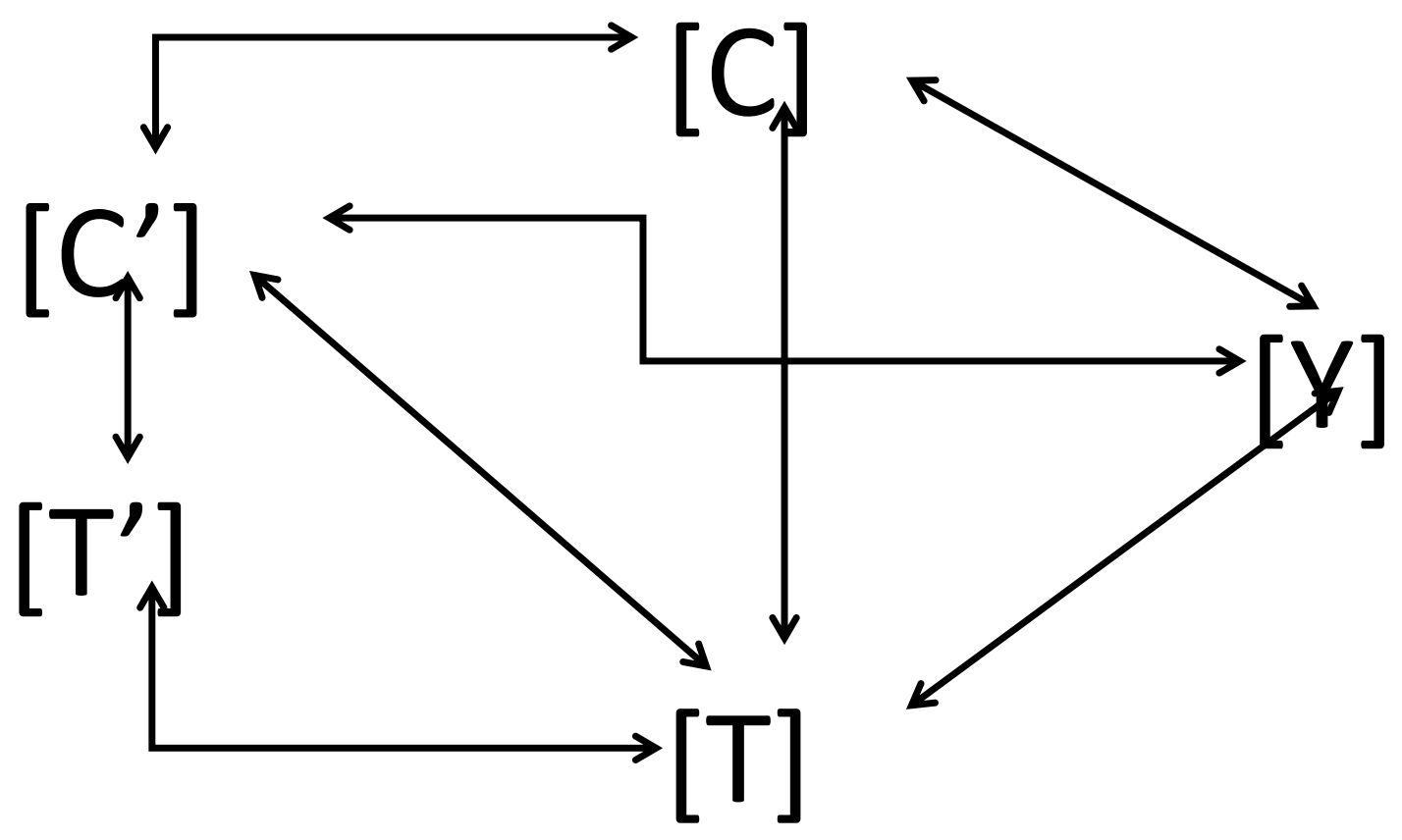

Figura 6 - Produto e serviço como uma conjunção de características e competências.

Adaptado de Gallouj e Savona (2010).Towards a theory of innovation in services: a state of art.

A tipologia de Gallouj (2002) contempla seis modelos de inovação em serviços não excludentes entre si, conforme Quadro 2.

\begin{tabular}{|c|c|}
\hline Modos de inovação & Características da Inovação \\
\hline Radical & $\begin{array}{l}\text { Definição restrita: criação de um novo conjunto de } \\
\text { características }\left[\mathrm{C}^{*}, \mathrm{C}^{*}, \mathrm{Y}^{*} \mathrm{e} \mathrm{X}^{*}\right] \text {. } \\
\text { Definição ampla: criação de um novo conjunto de } \\
\text { características }\left[\mathrm{C}^{*}, \mathrm{C}^{*} \text { e } \mathrm{X}^{*}\right] \text {, mesmo que [Y] } \\
\text { permaneça inalterado. }\end{array}$ \\
\hline Melhoria & Acréscimo na qualidade das características. \\
\hline Incremental & Acréscimo ou decréscimo de características. \\
\hline Formalização & Formatação e padronização de características. \\
\hline Ad hoc & Produção de novos componentes [C] \\
\hline Recombinativa & $\begin{array}{l}\text { Combinação ou fragmentação de grupos de } \\
\text { características. }\end{array}$ \\
\hline
\end{tabular}

Quadro 2 - Tipologia de inovação em serviços.

Fonte: Adaptada de Gallouj (2002). Innovation in the service economy: the wealth of nations. (p.71). Cheltenham: Edward Elgar. 
A inovação radical envolve a criação de um produto ou serviço totalmente novo, os vetores $\left[\mathrm{C}^{*}, \mathrm{C}^{*}, \mathrm{Y}^{*}\right.$ e $\left.\mathrm{X}^{*}\right]$ são inteiramente modificados, ou os vetores $\left[\mathrm{C}^{*}, \mathrm{C}^{*}, \mathrm{X}^{*}\right]$ são inteiramente modificados e $[\mathrm{Y}]$ permaneça inalterado (Gallouj, 2002). Desta forma, as competências são alteradas, pois não existiam no sistema antigo e se adaptam as novas características finais e técnicas que foram transformadas no sistema novo.

A inovação de melhoria frequentemente é o resultado do processo contínuo de aprendizagem da organização o que resulta num acréscimo da qualidade nas características $[\mathrm{C}]$ ou $[\mathrm{X}]$, que gera um aumento no valor final de $[\mathrm{Y}]$, sem alterar a estrutura dos vetores.

A inovação incremental não altera a estrutura geral do sistema, mas ocasiona uma mudança por meio da adição, subtração (eliminação) ou substituição de componentes e características ao $[\mathrm{X}]$ e/ou $[\mathrm{Y}]$.

A inovação de formalização é uma otimização do processo pelo desenvolvimento no nível de padronização das diversas características do serviço. Essa inovação consiste na visibilidade e no grau de padronização dos componentes e não nas variações quantitativas e qualitativas das características. A formalização simplifica a visualização das características tornando-as mais concretas e específicas, o que possibilita a replicação e facilita outros tipos de inovação (Gallouj, 2002).

A inovação ad hoc corresponde a uma construção social de uma solução para um problema específico apresentado pelo cliente, nessa construção interativa entre fornecedor e cliente, o vetor [Y] é único e os vetores [C] e [X] sofrem alterações (Gallouj, 2002). São inovações acidentais (não planejadas) e não reconhecidas como inovações até o final da prestação do serviço. Os novos conhecimentos e competências originados da inovação ad hoc podem ser formalizados e codificados para possibilitar a duplicação em diferentes circunstâncias (Gallouj, 2002). Esse tipo de inovação possui uma especial importância nos serviços intensivos de conhecimento.

A inovação recombinativa ou por recombinação é quando novas combinações de características técnicas ou finais são criadas com base na "reutilização" ou na "reciclagem" de componentes ou características existentes, mas que não resulta necessariamente em produtos radicalmente novos (Gallouj, 2002). Esse tipo de inovação possui importância no desenvolvimento de software com vistas a redução de custos, pode ser apontada como inovação desde que gere ganhos qualitativos com a mobilização da combinação de novos recursos. 
Para fins desta pesquisa, a tipologia de inovações proposta por Gallouj (2002) será adotada, por melhor caracterizar o objeto de estudo. As inovações de conteúdo são: Radical, Melhoria e Incremental, enquanto que as inovações de processo são: Formalização, Ad hoc e Recombinativa. Neste trabalho a ênfase é nos modelos que permitam a verificação de inovação de conteúdo. Além disso, os modos de inovação "Radical"; "Melhoria" e "Incremental", antecedem os outros modos de inovação, ou seja, as inovações "Formalização", "Ad hoc" e "Recombinativa" que passam por pelo menos um dos três tipos de inovação para ser concluída.

\subsection{Resultados da inovação no setor público}

O resultado do processo de inovação deve ser mensurado por meio de indicadores, por exemplo, melhoria na entrega dos serviços, por causa disso nas últimas décadas o setor público tem adquirido e adaptado do setor privado vários indicadores que são referentes a consumidores e inerentes ao mercado privado, sem analisar as especificidades do setor público (Kattel et al., 2014).

As organizações públicas podem ofertar incontáveis elementos que podem ser mensurados (Kuhlmann, 2010). Uma das diferenças entre o setor privado e o público é o objetivo principal, enquanto uma empresa do setor privado busca essencialmente o lucro, uma organização pública tem objetivos mais generalizados, como por exemplo, fornecer educação e saúde para os cidadãos (Bugge, M., Mortensen, P. S., \& Bloch, 2011). Como existem vários objetivos para as inovações nas organizações públicas, foram elencados 4 (quatro) resultados principais que são: melhoria na imagem e relações institucionais; melhoria na entrega e/ou qualidade dos serviços; melhoria na gestão organizacional e melhoria no clima organizacional.

A melhoria na imagem e relações institucionais é um resultado da inovação, pois é composto de elementos como maior capacidade de resolver desafios institucionais e outros desafios políticos relevantes (Bloch, 2011). As questões relacionadas com a ética, transparência e prestígio também influenciam a imagem da organização pública (Newcomer \& Allen, 2010). 
No que se refere a entrega/qualidade nos serviços é um dos principais resultados esperados no serviço público, conforme Bloch (2011), alguns setores essa é uma necessidade constante, como nos setores educacionais (Newcomer \& Allen, 2010).

Em relação a melhoria da gestão organizacional é um resultado recorrente, pois representa ganhos de eficiência e produtividade (Bugge, M., Mortensen, P. S., \& Bloch, 2011), que ocasionam melhores desempenhos para a organização (Newcomer \& Allen, 2010).

O clima organizacional envolve melhoria nas condições e trabalho (Bloch, 2011) e aspectos de da cultura organizacional e aumento da satisfação dos colaboradores (Mustafid \& Anggadwita, 2013).

O Quadro 3 consolida os quatro tipos de resultados que serão mensurados nessa pesquisa.

\begin{tabular}{|c|c|c|}
\hline Resultado (Melhoria) & Definiçãa & Referências \\
\hline $\begin{array}{l}\text { Na imagem e relações } \\
\text { institucionais. }\end{array}$ & $\begin{array}{l}\text { Consequências ou impactos } \\
\text { positivos na imagem da } \\
\text { organização e em suas relações. }\end{array}$ & $\begin{array}{l}\text { (Newcomer \& Allen, 2010) (2010), } \\
\text { e (Bloch, 2011). }\end{array}$ \\
\hline $\begin{array}{c}\text { Na entrega e/ou qualidade dos } \\
\text { serviços. }\end{array}$ & $\begin{array}{l}\text { Consequências ou impactos } \\
\text { positivos na qualidade do serviço e } \\
\text { nas organizações }\end{array}$ & $\begin{array}{l}\text { (Newcomer \& Allen, 2010) (2010), } \\
\text { e (Bloch, 2011). }\end{array}$ \\
\hline Gestão Organizacional. & $\begin{array}{l}\text { Consequências ou impactos } \\
\text { positivos na gestão das instituições. }\end{array}$ & $\begin{array}{l}\text { (Newcomer \& Allen, 2010) e } \\
\text { (Bugge, M., Mortensen, P. S., \& } \\
\text { Bloch, 2011). }\end{array}$ \\
\hline Clima Organizacional. & $\begin{array}{l}\text { Consequências ou impactos } \\
\text { positivos no clima organizacional } \\
\text { das instituições. }\end{array}$ & $\begin{array}{l}\text { (Mustafid \& Anggadwita, 2013) e } \\
\text { (Bloch, 2011). }\end{array}$ \\
\hline
\end{tabular}

Quadro 3 - Resultados da inovação

Fonte: Elaborado pelo autor.

\subsection{Modelo teórico da pesquisa}

O modelo proposto contém três hipóteses e busca verificar se existe a relação entre modos de inovação e resultados de inovação, capacidade de inovação e os modos de 
inovação, bem como busca verificar a relação entre modos de inovação, capacidade de inovação e resultados de inovação.

As hipóteses serão verificadas por meio de uma análise inferencial utilizando a regressão logística para verificar o aumento da probabilidade da variável de saída ou resultante, a partir de valores das variáveis previsoras. A regressão logística pode ser expressa com a seguinte equação:

$$
P(Y)=\frac{1}{1+e^{-\left(b_{0}+b_{1} X_{1}+b_{2} X_{2+}+\cdots+b_{n} X_{n}+\varepsilon\right)}}
$$

$\mathrm{P}(\mathrm{Y})=$ probabilidade de $\mathrm{Y}$ ocorrer;

$\mathrm{e}=$ base dos logaritmos naturais;

$\mathrm{X}_{1}=$ variável previsora 1 ;

$\mathrm{X}_{2}=$ variável previsora 2 ;

$\mathrm{X}_{\mathrm{n}}=$ variável previsora $\mathrm{N}$;

$\mathrm{b}_{\mathrm{o}}=$ constante;

$\mathrm{b}_{1}=$ coeficiente agregado ao previsor $\mathrm{X}_{1}$

$\mathrm{b}_{2}=$ coeficiente agregado ao previsor $\mathrm{X}_{2}$;

$b_{n}=$ coeficiente agregado ao previsor $X_{n}$.

Um indicador importante para interpretação da regressão logística é o exp b, que indica a mudança de probabilidade após a mudança de uma unidade do previsor (Field, 2013). O exp b pode ser expresso com a seguinte equação:

$$
\exp b=\frac{\text { Probabilidade após a mudança de uma unidade no previsor }}{\text { Probabilidade original }}
$$


Se o exp b for maior que 1 indica que se o previsor aumentar as chances da saída ocorrer aumentam. Contudo, se exp b for menor que 1 indica que se o previsor aumentar, as chances de saída ocorrer diminuem. O software utilizado para as análises descritiva e inferencial foi o IBM SPSS versão 20.

Para Hughes et al. (2011) os modos de inovação influenciam o resultado de inovação e aumentam o desempenho da organização. No mesmo sentido De Vries et al. (2016) indicam que os modos de inovação geram resultados para aumentar a eficiência e eficácia das organizações públicas. Desta forma, obtêm-se a H1:

\section{H1 - A presença de modos de inovação aumenta a probabilidade de ocorrência de resultados da inovação.}

A capacidade de inovação está relacionada com as condições exigidas para que a inovação evolua, sendo precursora dos modos de inovação (Hughes et al., 2011). A capacidade de inovação antecede os modos de inovação e são responsáveis por facilitarem todo o referido processo (De Vries et al., 2016). Assim, obtêm-se a H2:

H2 - A presença de capacidade de inovação aumenta a probabilidade de modos de inovação.

Os resultados da inovação são alcançados devido à influência de variáveis de capacidade e de modo de inovação (Hughes et al., 2011). Os resultados de inovação estão ligados aos modos de inovação e as capacidades, e frequentemente associados aos resultados de efetividade da entrega no serviço público (De Vries et al., 2016). Desta forma, obtêm-se $\mathrm{H} 3$ :

H3 - A presença de modos de inovação e capacidades de inovação aumentam a probabilidade de ocorrência de resultados da inovação.

As relações entre as variáveis propostas por meio das hipóteses supracitadas podem ser observadas na Figura 7. Adicionalmente, deve ser destacado que as relações também podem ser obtidas por meio dos modelos internacionais de mensuração da inovação, notadamente o modelo NESTA (National Endowement for Science Technology and the Arts) e o modelo 
APSII (Australian Public Sector Innovation Indicators Project), pois esses modelos indicam as mesmas relações propostas na figura 7 , e são modelos utilizados para inovação no setor público em outros países.

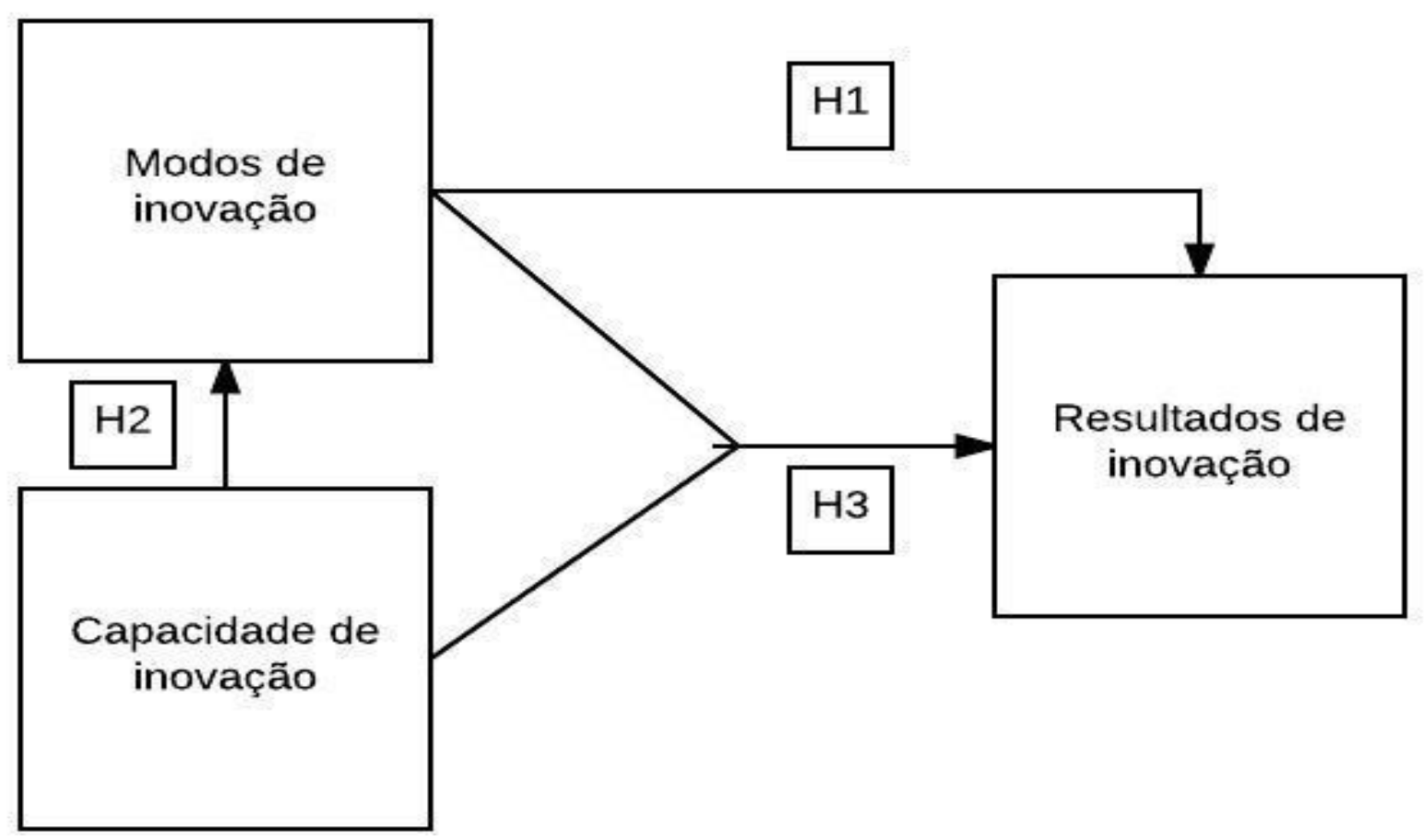

Figura 7 - Modelo estrutural da pesquisa

Fonte: Elaborado pelo autor

Para facilitar a compreensão das hipóteses e de como o modelo será verificado foi elaborado o Quadro 4, contendo as três hipóteses.

\begin{tabular}{|c|c|c|c|}
\hline${\text { Hipótese }{ }^{\circ}}^{*} 1$ & Antecedente/Previsor/X & Resultante/Saída/Y & Referências \\
\hline & Modos de inovação & Resultados de inovação & $\begin{array}{c}\text { (De Vries et al., 2016); } \\
\text { (Hughes et al., } \\
2011)\end{array}$ \\
\hline 2 & Capacidades de inovação & Modos de inovação & $\begin{array}{c}\text { (De Vries et al., 2016); } \\
\text { (Hughes et al., 2011) }\end{array}$ \\
\hline 3 & Modos de inovação e capacidades de & Resultados de inovação & $\begin{array}{c}\text { (De Vries et al., 2016); } \\
\text { (Hughes et al., 2011) }\end{array}$ \\
\hline
\end{tabular}

Quadro 4 - Referências das hipóteses

Fonte: Elaborado pelo autor 
Para operacionalizar as hipóteses verificadas na figura 7, foi elaborado o quadro 5 que permite uma melhor compreensão do trabalho desenvolvido neste estudo. Assim, a combinação de cada área de inovação possui uma divisão, pois tipos de inovação estão divididos em três (radical, melhoria e incremental), capacidade de inovação em 7 (liderança transformadora, intenção estratégica de inovar, gestão de pessoas para inovação, conhecimento do usuário e do ambiente, gestão estratégica da tecnologia, organicidade da estrutura organizacional e gestão de projetos) e resultado em 4 (melhoria na entrega e/ou qualidade dos serviços, melhoria na gestão organizacional, melhoria na imagem e relações institucionais e melhoria do clima organizacional).

A variável dependente deve ter somente uma saída, isto significa que quando a variável de saída é o resultado de inovação serão testadas 4 possibilidades na variável dependente, quando for testada a variável dependente tipo de inovação serão testadas 3 possibilidades. A divisão em 11 (onze) regressões para facilitar a verificação das hipóteses deste trabalho, conforme o Quadro 5.

\begin{tabular}{|c|c|c|}
\hline Identificação & Descrição & Verificação \\
\hline H1 & $\begin{array}{l}\text { A presença de modos de inovação aumenta a probabilidade de } \\
\text { ocorrência de resultados da inovação. }\end{array}$ & Verificar \\
\hline $1^{\mathrm{a}}$ regressão & $\begin{array}{l}\text { A presença de modos de inovação aumenta a probabilidade de ocorrência de } \\
\text { inovação na imagem e relações institucionais. }\end{array}$ & Verificar \\
\hline $2^{\mathrm{a}}$ regressão & $\begin{array}{l}\text { A presença de modos de inovação aumenta a probabilidade de ocorrência na } \\
\text { entrega e/ou qualidade dos serviços. }\end{array}$ & Verificar \\
\hline $3^{\mathrm{a}}$ regressão & $\begin{array}{l}\text { A presença de modos de inovação aumenta a probabilidade de ocorrência de } \\
\text { Gestão Organizacional. }\end{array}$ & Verificar \\
\hline $4^{\mathrm{a}}$ regressão & $\begin{array}{l}\text { A presença de modos de inovação aumenta a probabilidade de ocorrência de } \\
\text { Clima Organizacional. }\end{array}$ & Verificar \\
\hline $\mathrm{H} 2$ & $\begin{array}{l}\text { A presença de capacidade de inovação aumenta a probabilidade de } \\
\text { modos de inovação }\end{array}$ & Verificar \\
\hline $5^{\mathrm{a}}$ regressão & $\begin{array}{l}\text { A presença de capacidade de inovação aumenta a probabilidade de uma } \\
\text { inovação radical }\end{array}$ & Verificar \\
\hline $6^{\mathrm{a}}$ regressão & $\begin{array}{l}\text { A presença de capacidade de inovação aumenta a probabilidade de uma } \\
\text { inovação de melhoria }\end{array}$ & Verificar \\
\hline $7^{\mathrm{a}}$ regressão & $\begin{array}{l}\text { A presença de capacidade de inovação aumenta a probabilidade de uma } \\
\text { inovação incremental }\end{array}$ & Verificar \\
\hline H3 & $\begin{array}{l}\text { A presença de modos de inovação e capacidades de inovação aumentam } \\
\text { a probabilidade de ocorrência de resultados da inovação. }\end{array}$ & Verificar \\
\hline $8^{\mathrm{a}}$ regressão & $\begin{array}{l}\text { A presença de modos de inovação e capacidades de inovação aumentam a } \\
\text { probabilidade de ocorrência de inovação na imagem e relações } \\
\text { institucionais. }\end{array}$ & Verificar \\
\hline $9^{a}$ regressão & $\begin{array}{l}\text { A presença de modos de inovação e capacidades de inovação aumentam a } \\
\text { probabilidade de ocorrência na entrega e/ou qualidade dos serviços. }\end{array}$ & Verificar \\
\hline $10^{\mathrm{a}}$ regressão & $\begin{array}{l}\text { A presença de modos de inovação e capacidades de inovação aumentam a } \\
\text { probabilidade de ocorrência de Gestão Organizacional. }\end{array}$ & Verificar \\
\hline $11^{\mathrm{a}}$ regressão & $\begin{array}{l}\text { A presença de modos de inovação e capacidades de inovação aumentam a } \\
\text { probabilidade de ocorrência de Clima Organizacional. }\end{array}$ & Verificar \\
\hline
\end{tabular}

Quadro 5 - Hipóteses do estudo

Fonte: Elaborado pelo autor 
Desta forma, para se verificar as relações propostas no modelo da Figura 7 serão efetuadas 11 (onze) regressões logísticas, sendo 4 (quatro) para verificar H1, 3 (três) para verificar H2 e 4 (quatro) para verificar H3, de modo a alcançar o exposto no Quadro 5. 


\section{Método}

Nesta seção são apresentados os procedimentos a serem adotados na presente pesquisa, que são tipo e descrição geral da pesquisa, caracterização do setor, população, amostra e participantes do estudo e procedimento de análise de dados.

O método está aderente ao problema de pesquisa formulado, com os objetivos geral e específicos e com os princípios conceituais elencados.

\subsection{Tipo e descrição geral da pesquisa}

A presente pesquisa pode ser caracterizada como descritiva e explicativa, pois tem o objetivo de verificar a relação entre capacidades, modos e resultados de inovação nas experiências inovadores em gestão na Administração Pública Federal, a partir da análise de experiências inovadoras realizadas pela Escola Nacional de Administração Pública - Enap.

Para Hair, Babin, Money e Samouel (2005) uma pesquisa explicativa tem seus planos estruturados e especificamente criados para medir as características descritas em uma questão de pesquisa. Nesse mesmo sentido Gil (2008) declara que as pesquisas explicativas têm como propósito identificar fatores que determinam ou contribuem para a ocorrência de fenômenos e aprofundam o conhecimento da realidade.

A técnica de pesquisa pode ser caracterizada como documental, que segundo Marconi e Lakatos (2010) é uma técnica que utiliza materiais que não receberam um tratamento analítico, ou seja, pode ser reelaborados de acordo com os objetivos da pesquisa.

Para Flick (2009) a pesquisa documental pode considerar dois pontos: i) a utilização de dados solicitados para o estudo e/ou ii) documentos existentes que foram produzidos para outros fins. No caso do presente estudo será utilizado documentos existentes que foram produzidos para outros fins, que é o caso dos relatos das práticas de inovação premiadas no concurso da Escola Nacional de Administração Pública - Enap. Assim, as informações obtidas foram tratadas por meio de uma análise de conteúdo usando três passos, conforme descrito por Bardin (2011).

O primeiro foi uma pré-análise que consistiu na seleção de documentos descritos e organização do material para torná-lo mais operacional. O segundo passo foi a exploração do material e a definição de categorias ou sistemas de codificação, sendo que a categoria modelo 
foi selecionada após uma revisão da literatura e as demais categorias foram selecionadas por meio de uma análise de conteúdo e só depois comparadas com a literatura para validar as variáveis escolhidas. A última etapa consistiu no tratamento de dados, inferência e interpretação, no intuito de obter uma maior confiabilidade nos dados, assim executou-se uma triangulação entre os pesquisadores.

Após a etapa de codificação os dados foram inseridos em uma base de dados, sendo que cada categoria apresenta um formato binário, o número 1 representa a presença na categoria da experiência selecionada e o número 0 a ausência. Esse formato foi escolhido, pois as categorias não são mutuamente excludentes, tais como barreiras, facilitadores, indutores e benefícios. Em alguns casos foram verificadas a presença de uma categoria na experiência selecionada.

\subsection{População, amostra e participantes do estudo}

Uma população é o conjunto formado por indivíduos ou objetos que têm pelo menos uma variável comum e observável (Morettin, 2010). Desta forma, uma amostra é um subgrupo dos elementos de uma população utilizada para a pesquisa (Malhotra, 2012). No presente trabalho, a população é composta de 286 casos, que foram coletados entre os anos de 1999 e 2014, que representa as experiências premiadas.

Apesar do concurso ter iniciado em 1996, as três primeiras edições foram descartadas por não apresentarem um padrão de descrição adequado, pois apresentava apenas um breve relato da experiência, o padrão com um relato mais detalhado foi adotado a partir da quarta edição. Nas três primeiras edições o objetivo era premiar as iniciativas de mudança e não estavam focadas em identificar com rigor as inovações.

A abrangência do prêmio de inovação é nacional e podem participar do concurso todas as iniciativas desenvolvidas em órgãos e entidades do Poder Executivo Federal (ministérios, agências, autarquias, fundações, empresas públicas e sociedades de economia mista) e em organizações sociais (definidas e qualificadas apenas pelo Governo Federal, de acordo com a Lei $\mathrm{n}^{\circ}$ 9.637/1998). 


\subsection{Procedimento de análise de dados}

A primeira parte desta pesquisa foi a participação na elaboração do banco de dados InnovaPublic que foi criado utilizando a análise de conteúdo descrita acima e com a participação de diversos pesquisadores do Núcleo de Estudos e Pesquisas em Inovação e Estratégia - NINE/UnB, os protocolos para criação da base de dados das variáveis de interesse desta pesquisa, estão no anexo A e B. A triangulação entre pesquisadores foi efetuada da seguinte forma, cada dupla de pesquisadores recebia o mesmo relato para verificar a presença ou ausência de determinada característica, após a conclusão do trabalho era efetuada uma consolidação dos dados e no caso de existência de divergência o problema era submetido a um terceiro pesquisador para solução.

As análises das relações entre as variáveis foram efetuadas pela utilização de regressão logística, pois as variáveis assumem um formato dicotômico. O formato dicotômico significa que as variáveis qualitativas só permitem resposta do tipo sim/não ou ausência/presença. As variáveis qualitativas são definidas por categorias, o que representa uma classificação dos indivíduos e podem ser divididas em nominais e ordinais. As nominais não existem ordenação dentre as categorias, fumante/não fumante, sexo. Já nas ordinais existe ordenação, por exemplo, escolaridade (ensino fundamental, médio, superior).

A regressão logística tem como objetivo produzir um modelo que permita a predição de valores, a partir de um conjunto de observações, a partir de uma série de variáveis que são frequentemente binárias. Ela é uma regressão múltipla, mas com variável de saída categórica dicotômica e variáveis previsoras contínuas ou categóricas. Assim, podemos prever a qual de duas categorias é provável que uma pessoa pertença dado certas informações.

Um dos principais índices da regressão logística é o Exp (B) que é um indicador da mudança nas probabilidades resultantes da mudança de uma unidade no previsor, se o valor for maior que 1 significa que quando o previsor (X) aumenta, as chances de saída (Y) ocorrer aumentam. Já o valor menor que 1 indica que quando o previsor aumenta (X), as chances da saída ocorrer diminuem (Y).

Para Field, (2013) o resultado (saída) com variáveis dicotômicas viola o princípio da linearidade, pois a hipótese da regressão linear é que o relacionamento entre as variáveis seja linear, por isso não é permitido a utilização da regressão linear.

Assim, para testar a relação entre as variáveis, as seguintes hipóteses serão testadas: 
a) modos de inovação (antecedente) e resultados de inovação (resultante);

b) capacidades de inovação (antecedente) e modos de inovação (resultante);

c) capacidades e modos de inovação (antecedentes) e resultados de inovação (resultante);

Será utilizado o teste qui-quadrado de Pearson para verificar se há relação entre duas variáveis categóricas. O teste de Pearson é um teste estatístico para verificar se o conjunto de dados categóricos relacionados diferem do acaso, ele testa se duas variáveis categóricas dispostas em uma tabela de contingência estão associadas. (Field, 2013). 


\section{Resultados}

Para avaliar os resultados foram efetuadas duas etapas, sendo a primeira uma análise descritiva e a outra inferencial. A análise descritiva das experiências permite uma descrição dos dados para compreender a distribuição deles. A outra parte que é a análise inferencial permite utilizar métodos estatísticos para inferir a partir de uma população (ou parte dela) a extrapolação dos dados. O método inferencial é a regressão logística que é a regressão recomendada para ser utilizada quando as variáveis possuem um formato dicotômico (binário).

\subsection{Análise descritiva das experiências}

A análise descritiva permite agrupar os dados para uma avaliação da sua distribuição e frequência. Desta forma, serão apresentados os dados característicos das experiências, após serão apresentados os dados das variáveis de interesse desta pesquisa.

O nível de atuação do governo está classificado como administração centralizada e administração descentralizada. A administração central compreende as organizações que estão localizadas no Distrito Federal, enquanto que administração descentralizada compreende as organizações que estão em outros estados da federação, ou seja, fora do Distrito Federal.

A tabela 1 apresenta a frequências dos casos, percebe-se que a administração centralizada concentra a maioria dos casos (183) que representa 64\%, enquanto que a administração descentralizada tem 103 casos, o que representa 36\% dos casos. Alguns motivos podem ser apresentados para a centralização dos casos. O primeiro seria que o DF concentra a maioria dos entes públicos federais, principalmente as atividades de direção. Segundo a Enap está localizada no DF o que pode significar uma influência mais geográfica do prêmio, pois os servidores lotados em Brasília teriam um contato maior com a Enap, proporcionado à submissão das experiências pela administração central. Terceiro a difusão do concurso poderia ser maior no DF, apesar das informações estarem disponíveis na internet, o contato entre os servidores de Brasília-DF com a Enap tende a ser maior, pois os custos de 
deslocamento são menores e custos com hospedagem para servidores lotados em Brasília são inexistentes.

Tabela 1 - Frequência de casos por nível de atuação do governo.

\begin{tabular}{|c|c|c|}
\hline Nível de Atuação & $\mathrm{N}^{\circ}$ de Casos & Percentual (\%) \\
\hline Administração Centralizada & 183 & 64,0 \\
\hline Administração Descentralizada & 103 & 36,0 \\
\hline Total & 286 & 100 \\
\hline
\end{tabular}

Nota. Fonte: Elaborado pelo Autor

A estrutura da administração está classificada como direta e indireta. A administração direta é composta por órgãos que não são dotados de personalidade jurídica, orçamento, patrimônio ou autonomia e estão ligadas diretamente à União (Poder Executivo Federal), por exemplo, Ministério do Planejamento, Desenvolvimento e Gestão, Ministério da Fazenda, Secretária do Tesouro, Receita Federal. A administração indireta é composta por entidades que são dotadas de personalidade jurídica, possuem personalidade jurídica, orçamento, autonomia administrativa e patrimônio. A administração indireta compreende as autarquias, fundações públicas, empresas públicas e sociedades de economia mista, por exemplo, Banco Central (autarquia), Fundação nacional do índio - FUNAI (fundação pública), Caixa Econômica Federal (empresa pública), Banco do Brasil (sociedade de economia mista).

A Tabela 2 apresenta um predomínio da administração direta, visto que administração central é composta por inúmeros órgãos que pertencem a administração direta, o predomínio da administração direta era esperado. Outra questão é que as entidades da administração indireta, como por exemplo, o Banco do Brasil possuem estrutura de treinamento própria, no caso a Universidade Corporativa Banco do Brasil - UniBB, não sendo utilizada a Enap como local de treinamento.

Tabela 2 - Frequência de casos pela estrutura da administração

\begin{tabular}{|c|c|c|}
\hline Estrutura da Administração & $\mathrm{N}^{\circ}$ de Casos & Percentual (\%) \\
\hline Administração Direta & 158 & 55,2 \\
\hline Administração Indireta & 128 & 44,8 \\
\hline Total & 286 & 100 \\
\hline
\end{tabular}

Nota. Fonte: Elaborado pelo Autor 
A área temática está dividida em 5 (cinco) temas principais. Esses temas são definidos pela organização do prêmio e cada participante deve indicar o tema no momento da submissão. A área com o maior percentual é otimização e melhoria de processos $(23,1 \%)$, que está relacionada com a melhoria contínua e a racionalização dos processos da organização. A segunda é o planejamento e gestão organizacional (22,4\%), associada à gestão estratégica, gestão orçamentária e financeira, planejamento estratégico, gestão de custos, gestão do conhecimento, elaboração de índices de gestão e avaliação do desempenho. As categorias que representam atividade fim que são política pública $(19,9 \%)$ e prestação de serviços $(18,2 \%)$, estão em terceiro e quarto lugar respectivamente, estão relacionadas aos casos de criação, implementação e avaliação de políticas públicas e a processos para ajudar diretamente os cidadãos. A última área temática é a gestão da informação $(16,4 \%)$ que é responsável por identificar as categorias informacionais, mapear fluxos formais de informação nos diferentes ambientes da organização e otimizar os canais com os cidadãos. A Tabela 3 apresenta a distribuição por área temática.

Tabela 3 - Frequência de casos por área temática

\begin{tabular}{|c|c|c|}
\hline Área Temática & $\mathrm{N}^{\circ}$ de Casos & Percentual (\%) \\
\hline Otimização e Melhoria de & 66 & 23,1 \\
Processos & & 22,4 \\
\hline $\begin{array}{c}\text { Planejamento e Gestão } \\
\text { Organizacional }\end{array}$ & 64 & 19,9 \\
\hline Política Pública & 57 & 18,2 \\
\hline Prestação de Serviços & 52 & 16,4 \\
\hline Gestão da Informação & 47 & 100 \\
\hline Total & 286 & \\
\hline
\end{tabular}

Nota. Fonte: Elaborado pelo Autor

No tocante as variáveis de interesse, a tabela 4 apresenta a primeira análise em relação a tipologia de Gallouj (2002) modificada para este trabalho, com os três modos de inovação, sendo que os modos de inovação de melhoria $(43,7 \%)$ e incremental $(44,4 \%)$ respondem pela quase totalidade das experiências, pois o modo de inovação radical apresente poucos casos $(11,9 \%)$. 
O predomínio em inovações incrementais e de melhorias já era esperado, pois a aversão ao risco minimiza uma dedicação a inovações radicais. Isto significa que melhorar um sistema que já apresenta resultados é menos arriscado do que implementar um sistema totalmente novo. $\mathrm{O}$ esforço inovativo num processo de melhoria/incremental também é menor e tende a ser menos oneroso do que num processo totalmente novo (inovação radical). Desta forma, a inovação radical que é mais arriscada representou o menor número de observações. A Tabela 4 apresenta a distribuição de cada um dos modos de inovação.

Tabela 4 - Frequencia de casos de modos de inovação

\begin{tabular}{|c|c|c|}
\hline Modos de Inovação & $\mathrm{N}^{\circ}$ de Casos & Percentual (\%) \\
\hline Melhoria & 127 & 44,4 \\
\hline Incremental & 125 & 11,9 \\
\hline Radical & 34 & 100 \\
\hline Total & 286 & 73,7 \\
\hline
\end{tabular}

Nota. Fonte: Elaborado pelo Autor

A outra variável de interesse é a capacidade de inovação, como em um caso pode existir nenhuma, uma, ou mais de uma capacidade de inovação, o valor total de capacidades que é 1095 é superior ao número de casos que é 286. Ao dividir o número de capacidades pelo número de experiências o resultado é 3,83 capacidades/experiência. Isto significa que em cada experiência podemos observar mais de 3 capacidades em média, o que representa que cada caso estava relacionado com mais de uma capacidade.

A Tabela 5 apresenta a distribuição dos casos, sendo que o percentual (Base 286) significa o número de casos de capacidades de inovação identificadas dividido pelo total de experiências que é de 286 casos. Já o percentual (Base 1095) representa o número de capacidades de inovação identificadas dividido pelo total de capacidades de inovação que é de 1095 capacidades.

As capacidades com maior frequência foram gestão de pessoas para inovação $(75,5 \%)$, seguida pela gestão de projetos $(71,0 \%)$ e gestão estratégica da tecnologia $(59,8 \%)$, essas três primeiras capacidades estão associadas à gestão. As capacidades em gestão tem um escopo muito grande, o que facilita o seu relato e a sua identificação. Um dos objetivos do prêmio constante no Quadro 1, item a: "incentivar a implementação de iniciativas inovadoras de gestão, em organizações do Governo Federal, que contribuam para a melhoria dos serviços públicos", ou seja, o participante do concurso pode estar inclinado a demonstrar essa capacidade, o que facilita a identificação, isto pode ser um dos motivos das maiores 
frequências de capacidades estarem associadas a gestão. Na sequência são as capacidades liderança transformadora $(57,0 \%)$, Organicidade da estrutura organizacional $(53,8 \%)$, conhecimento do cliente e do mercado (46,9\%), e intenção estratégica de inovar (18,9\%).

Tabela 5 - Frequência de casos de capacidade de inovação

\begin{tabular}{|l|c|c|c|}
\hline \multicolumn{1}{|c|}{ Capacidade percentual (\%) Base 286 } & Percentual (\%) Base 1095 \\
\hline $\begin{array}{l}\text { Gestão de pessoas para } \\
\text { inovação }\end{array}$ & 216 & 75,5 & 19,7 \\
\hline Gestão de projetos & 203 & 71,0 & 18,5 \\
\hline $\begin{array}{l}\text { Gestão estratégica da } \\
\text { tecnologia }\end{array}$ & 171 & 59,8 & 15,6 \\
\hline $\begin{array}{l}\text { Liderança transformadora } \\
\text { Organicidade da estrutura } \\
\text { organizacional }\end{array}$ & 154 & 57,0 & 14,9 \\
\hline $\begin{array}{l}\text { Conhecimento do cliente e do } \\
\text { mercado }\end{array}$ & 134 & 53,8 & 12,2 \\
\hline $\begin{array}{l}\text { Intenção estratégica de inovar } \\
\text { Total }\end{array}$ & 54 & 46,9 & 4,9 \\
\hline
\end{tabular}

Nota. Fonte: Elaborado pelo Autor

Por fim, a última variável de interesse é resultado. Como pode existir nenhum, um ou mais de um resultado em cada caso, o valor total do número de casos de resultados também é superior (536) ao valor de número de casos das experiências (286). Ao dividir o número de resultados pelo número de experiências o resultado é 1,87 resultados/experiência. Isto significa que em cada experiência podemos observar mais de 1,8 resultado em média, o que representa que cada caso estava relacionado com mais de um resultado. Isto pode indicar que a experiência teve como consequência mais de um resultado para a organização.

A Tabela 6 apresenta a distribuição dos casos, sendo que o percentual (Base 286) significa em o número de casos de resultado de inovação identificadas dividido pelo total de experiências que é de 286 casos. Já o percentual (Base 536) representa o número de resultados de inovação identificadas dividido pelo total de resultados de inovação que é de 536.

O resultado com maior frequência foi a melhoria na gestão organizacional $(69,6 \%)$, seguida de melhoria na entrega e/ou qualidade dos serviços $(69,2 \%)$ como no caso das capacidades o resultado gestão organizacional tem um escopo abrangente e pode ter facilitado 
o seu relato e a sua identificação. Na sequência os resultados de melhoria na imagem e relações institucionais $(34,6 \%)$ e melhoria no clima organizacional $(14 \%)$.

Tabela 6 - Frequência de casos de resultados de inovação.

\begin{tabular}{|c|c|c|c|}
\hline Resultado (Melhoria) & $\mathrm{N}^{\circ}$ de Casos & Percentual (\%) Base 286 & Percentual (\%) Base 536 \\
\hline Gestão Organizacional. & 199 & 69,6 & 37,1 \\
\hline $\begin{array}{c}\text { Na entrega e/ou qualidade } \\
\text { dos serviços. }\end{array}$ & 198 & 69,2 & 36,9 \\
\hline $\begin{array}{c}\text { Na imagem e relações } \\
\text { institucionais. }\end{array}$ & 99 & 34,6 & 18,5 \\
\hline Clima Organizacional. & 40 & 14,0 & 7,5 \\
\hline Total & 536 & & 100 \\
\hline
\end{tabular}

Nota. Fonte: Elaborado pelo Autor

\subsection{Análise inferencial das experiências}

$\mathrm{Na}$ análise inferencial estamos interessados em utilizar informações de uma amostra para acessar e tirar conclusões sobre um grupo maior que não temos acesso. No presente caso a regressão logística permite prever uma variável de saída categórica dicotômica em função de outras variáveis.

A alteração de metodologia e premiação ocorrida a partir do prêmio da ENAP em 2007 não alterou o comportamento das variáveis, pois foi realizado um teste de Qui-Quadrado que apresentou um valor de significância $\mathrm{p}>0,05$ para todas variáveis de interesse do estudo (modos, capacidades e resultados de inovação), o que indica que as evidências são insuficientes para rejeitar a hipótese nula de que as variáveis são independentes. Assim, a alteração da metodologia de avaliação do prêmio ocorrida a partir de 2007 não afetou o comportamento das variáveis, portanto as experiências dos períodos de 1999 a 2006 e 2007 a 2014 podem ser testadas em conjunto. Os resíduos foram utilizados para verificar a aderência do modelo, sendo considerados satisfatórios, não apresentando grandes discrepâncias, portanto o modelo foi considerado aderente. 


\subsubsection{Relação entre modos e resultados de inovação}

A primeira hipótese a ser testada no modelo de regressão logística foi a relação entre modos e resultados. Foram efetuadas quatro regressões logísticas, sendo uma para cada tipo de resultado de inovação. Nesta etapa buscou testar a hipótese H1 por meio das regressões logísticas $\left(1^{\mathrm{a}}, 2^{\mathrm{a}}, 3^{\mathrm{a}}\right.$ e $\left.4^{\mathrm{a}}\right)$, as relações significativas estão na Tabela 7 . As demais relações não foram verificadas no modelo de regressão e por isso não são apresentadas na Tabela 7. Os resultados estão aderentes, pois possuem um Qui-quadrado significativo $(\mathrm{p}<0,05)$.

Tabela 7 - A presença de modos de inovação aumenta a probabilidade de ocorrência de inovação na imagem e relações institucionais $\left(1^{\mathrm{a}}\right.$ regressão).

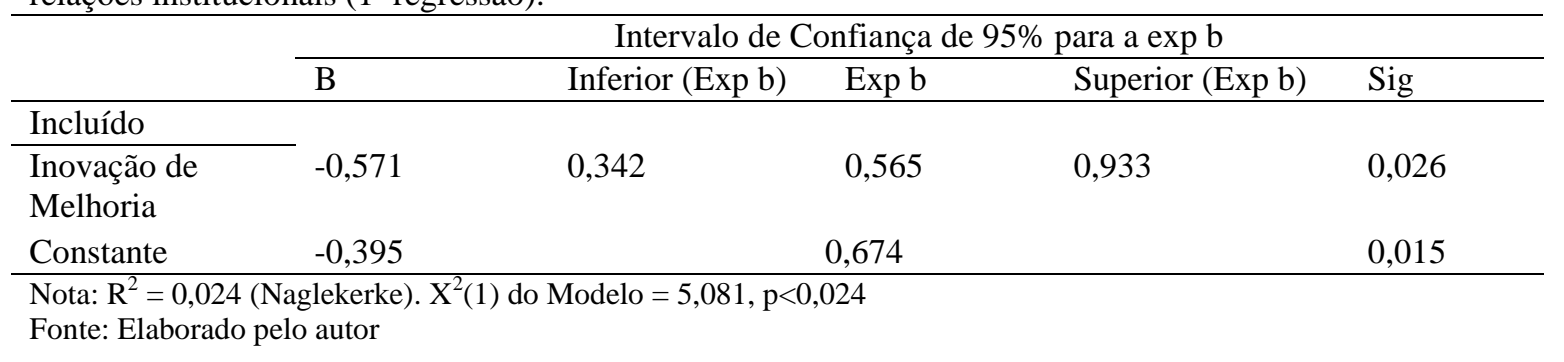

A hipótese $(\mathrm{H} 1)$ verificada por meio da $1^{\text {a }}$ regressão logística "A presença de modos de inovação aumenta a probabilidade de ocorrência de inovação na imagem e relações institucionais", apesar de ter sido detectada que a inovação de melhoria influencia na ocorrência de inovação de imagem, não foi o esperado. O Exp b é de 0,565 , ou seja, um valor inferior a 1, isto significa, que quanto mais o previsor (a inovação de melhoria) aumenta, a saída (melhoria na imagem e relações institucionais) diminui, ou seja, são inversamente proporcionais. Desta forma, a hipótese não foi verificada e será explicado adiante as possíveis causas da rejeição da hipótese.

A figura 8 apresenta as relações significativas da hipótese $\mathrm{H} 1$, sendo que a linha tracejada significa que o Exp é menor que 1 . 


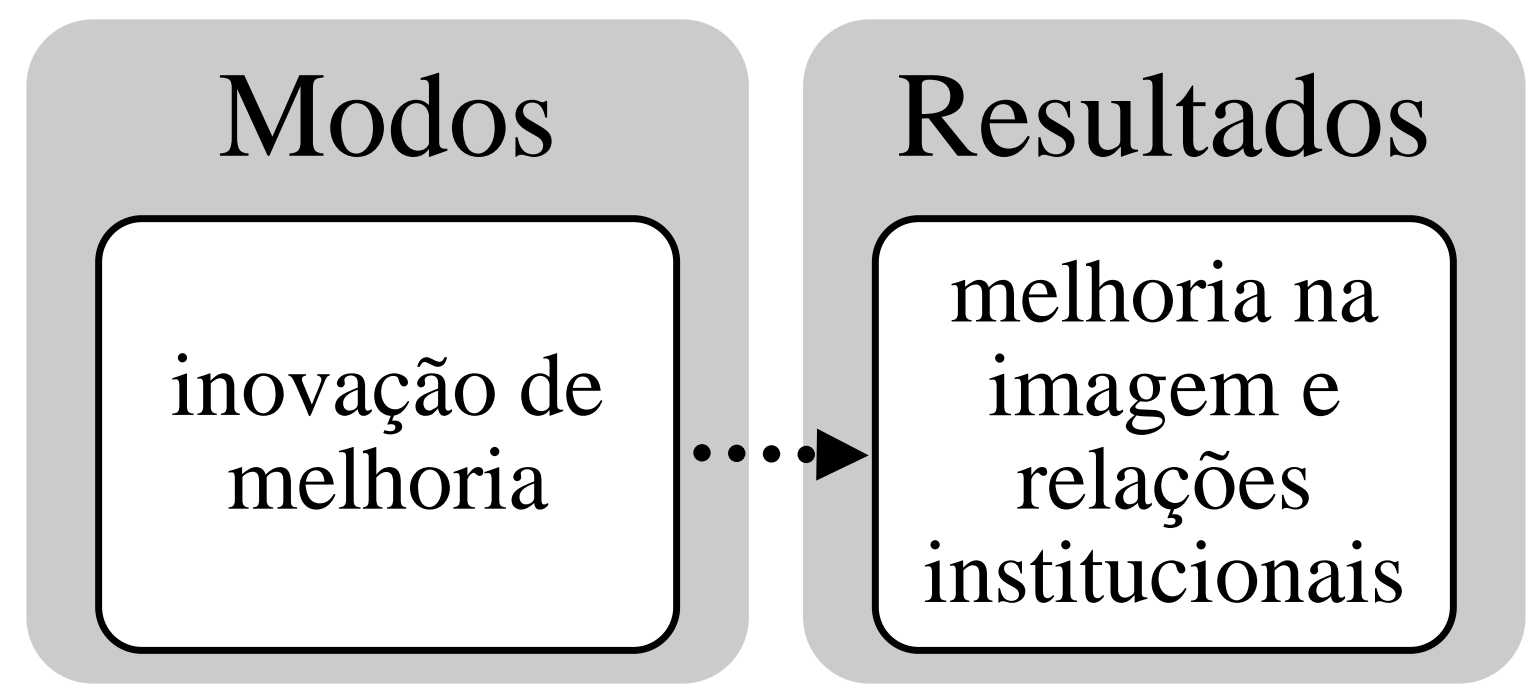

Figura 8 - Relações significativas H1

Fonte: Elaborado pelo Autor

Inicialmente pode parecer uma contradição, pois um aumento no esforço na atividade de inovação representou uma influência negativa no desempenho de inovação, mas um das consequências do esforço de inovação pode ser numa primeira etapa a diminuição do resultado, pois existe um tempo para que a inovação seja internalizada pela equipe para que possam ser observados os resultados. Como por exemplo, a introdução de um novo software para gerenciamento de processos, no início pode existir até uma rejeição dos servidores ao novo programa, o que impactaria diretamente o resultado. Após a fase de rejeição seria a fase do aprendizado que também resultaria em um impacto negativo, pois não estaria produzindo com a capacidade plena, somente após a completa absorção da inovação e que poderiam ser mensurados resultados efetivos. Os impactos negativos ou resistências dos funcionários são previsíveis no processo de inovação no setor público. (Bloch, 2011).

\subsubsection{Relação entre capacidades e modos de inovação}

A segunda hipótese a ser testada no modelo de regressão logística foi a relação entre capacidades e modos. Foram efetuadas três regressões logísticas para verificar a hipótese. Nesta etapa buscou testar a hipótese $\mathrm{H} 2$ por meio das regressões logísticas $\left(5^{\mathrm{a}}, 6^{\mathrm{a}}\right.$ e $\left.7^{\mathrm{a}}\right)$ que estão no Quadro 5, as relações significativas estão na Tabela 7. As demais relações não foram verificadas no modelo de regressão e por isso não são apresentadas na Tabela 7. Os resultados estão aderentes, pois possuem um Qui-quadrado significativo $(\mathrm{p}<0,05)$. 
Tabela 8 - A presença de capacidade de inovação aumenta a probabilidade de uma inovação incremental ( $7^{\mathrm{a}}$ regressão).

\begin{tabular}{llllll}
\hline & \multicolumn{5}{c}{ Intervalo de Confiança de 95\% para a exp b } \\
\cline { 2 - 5 } & $\mathrm{B}$ & Inferior $($ Exp b) & Exp b & Superior (Exp b) & Sig \\
\hline Incluído & 0,494 & 1,011 & 1,639 & 2,659 & 0,045 \\
\hline $\begin{array}{l}\text { Gestão de } \\
\text { Tecnologia }\end{array}$ & & & & 0,004 \\
\hline Constante & $-0,553$ & \multicolumn{5}{c}{0,575} & \\
\hline
\end{tabular}

Nota: R2 = 0,019 (Naglekerke). X2(1) do Modelo = 4,063, p<0,044

Fonte: Elaborado pelo autor

A hipótese $\mathrm{H} 2$ ( $7^{\mathrm{a}}$ regressão) “A presença de capacidade de inovação aumenta a probabilidade de uma inovação incremental", foi verificada na capacidade de gestão de tecnologia. O Exp b é de 1,639, ou seja, um valor superior a 1, isto significa, que quanto mais o previsor (gestão de tecnologia) aumenta a saída (inovação incremental), ou seja, são diretamente proporcionais.

A figura 9 apresenta as relações significativas da hipótese H2, sendo que a linha contínua representa que o Exp b é maior que 1.

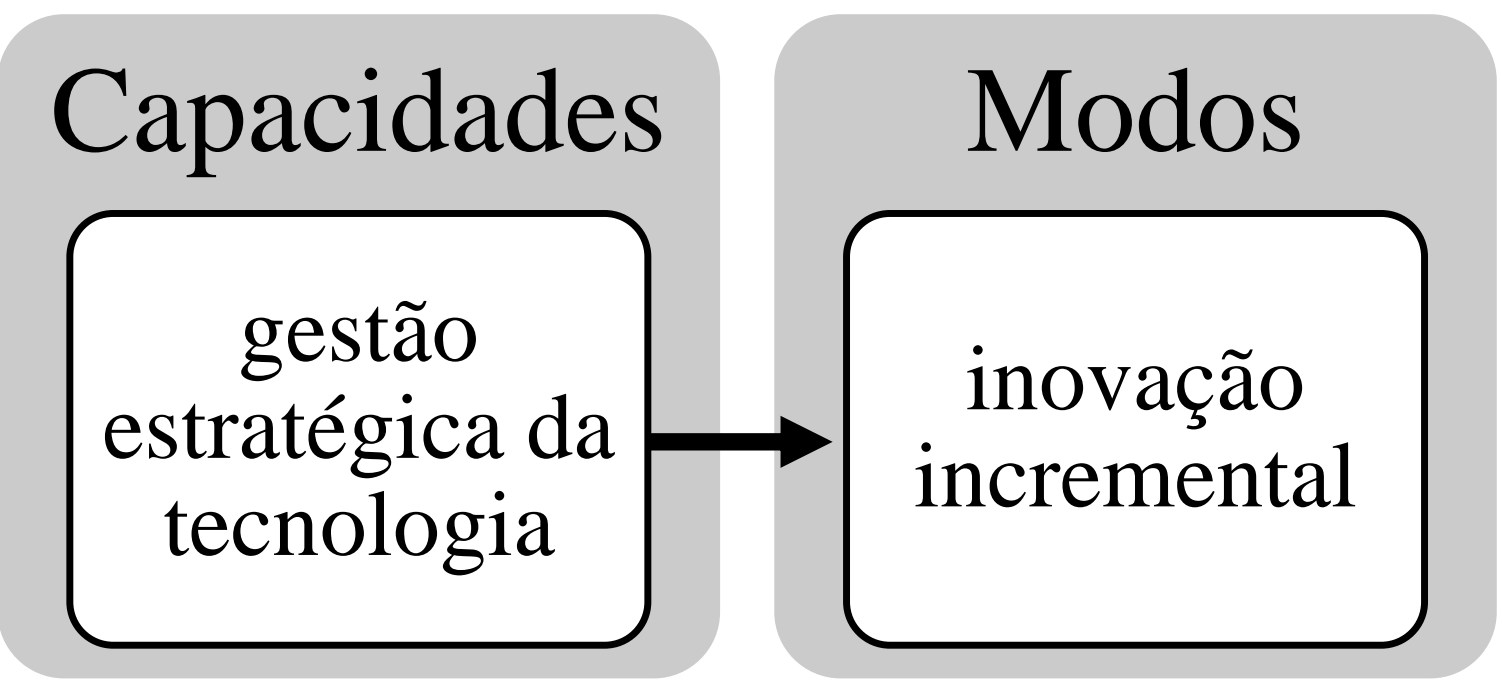

Figura 9 - Relações significativas H2

Fonte: Elaborado pelo Autor

Assim, a chance de ocorrer uma inovação incremental é 1,6 vezes maior quando existe a capacidade de inovação de gestão de tecnologia. A gestão de tecnologia que compreende a criação e desenvolvimento de tecnologia visando à criação de valor, sendo esse fator um importante atributo para melhorar o processo de inovação (Valladares et al., 2014). 
A influência entre capacidades de inovação sobre os modos de inovação encontra respaldo nos modelos internacionais de mensuração e também confirma a hipótese que a capacidade de inovação aumentaria a probabilidade dos modos de inovação. Para Hughes et al. (2011) capacidade de inovação descreve as principais atividades que influenciam de forma sustentável a inovação, que de acordo com os resultados obtidos neste trabalho, influenciam os modos de inovação.

\subsubsection{Relação entre capacidades, modos e resultados}

A terceira hipótese a ser testada no modelo de regressão logística foi a relação entre capacidades, modos e resultados. Foram efetuadas quatro regressões logísticas, sendo uma para cada tipo de resultados de inovação. Nesta etapa buscou testar a hipótese H3 por meio das regressões logísticas $\left(8^{\mathrm{a}}, 9^{\mathrm{a}}, 10^{\mathrm{a}}\right.$ e $\left.11^{\mathrm{a}}\right)$ que estão no Quadro 5. A seguir cada uma das relações será explicada. Sendo essa hipótese a que teve o maior número de relações significativas. Os resultados apresentados estão aderentes, pois possuem um Qui-quadrado significativo $(\mathrm{p}<0,05)$.

A tabela 9 apresenta os resultados significativos da hipótese $\mathrm{H} 3$ ( $8^{\mathrm{a}}$ regressão), as relações significativas ocorreram com as capacidades conhecimento do usuário e gestão de projetos e com o modo de inovação de melhoria.

Tabela 9 - A presença de modos de inovação e capacidades de inovação aumentam a probabilidade de ocorrência de inovação na imagem e relações institucionais. ( $8^{\text {a }}$ regressão).

\begin{tabular}{|c|c|c|c|c|c|}
\hline & \multicolumn{5}{|c|}{ Intervalo de Confiança de $95 \%$ para a exp b } \\
\hline & $\mathrm{B}$ & Inferior $(\operatorname{Exp} b)$ & Exp b & Superior (Exp b) & Sig \\
\hline Incluído & & & & & \\
\hline $\begin{array}{l}\text { Conhecimento do } \\
\text { cliente e do } \\
\text { mercado }\end{array}$ & 0,515 & 1,000 & 1,674 & 2,806 & 0,05 \\
\hline $\begin{array}{l}\text { Gestão de } \\
\text { Projetos }\end{array}$ & 0,839 & 1,240 & 2,313 & 4,317 & 0,008 \\
\hline $\begin{array}{l}\text { Inovação de } \\
\text { Melhoria }\end{array}$ & $-0,537$ & 0,349 & 0,584 & 0,979 & 0,041 \\
\hline Constante & $-1,291$ & & 0,275 & & 0,000 \\
\hline
\end{tabular}


A hipótese H3 ( $8^{a}$ regressão) "A presença de modos de inovação e capacidades de inovação aumentam a probabilidade de ocorrência de inovação na imagem e relações institucionais" foi verificada na capacidade conhecimento de usuários e gestão de projetos, sendo detectada uma influência negativa no modo inovação de melhoria.

As capacidades de inovação conhecimento de usuário e gestão de projetos apresentaram um Exp b maior que significa uma influência positiva no resultado, enquanto que o modo de inovação de melhoria apresentou um Exp b menor que 1, o que significa uma influência negativa no resultado. Desta forma, a hipótese foi verificada parcialmente.

As capacidades de inovação conhecimento de usuários e gestão de projetos apresentaram Exp b 1,674 e 2,323 respectivamente, o que indica uma relação positiva para o aumento da probabilidade do resultado melhoria na imagem de relações institucionais. A capacidade de inovação conhecimento dos usuários aumentou em 1,6 vezes a probabilidade de ocorrência do resultado melhoria na imagem e relações institucionais e a capacidade de inovação gestão de projetos aumentou em 2,3 a probabilidade de ocorrência daquele resultado. Contudo, o modo inovação de melhoria apresentou um Exp b de 0,584, o que indica uma grandeza inversamente proporcional, ou seja, quanto mais o previsor (a inovação de melhoria) aumenta, a saída (melhoria na imagem e relações institucionais).

A tabela 10 apresenta os resultados significativos da hipótese H3 (9 $9^{\text {a }}$ regressão), a relação significativa ocorreu somente com a capacidade liderança transformadora.

Tabela 10 - A presença de modos de inovação e capacidades de inovação aumentam a probabilidade de ocorrência na entrega e/ou qualidade dos serviços. ( $9^{a}$ regressão).

\begin{tabular}{|c|c|c|c|c|c|}
\hline & \multicolumn{5}{|c|}{ Intervalo de Confiança de $95 \%$ para a exp b } \\
\hline & $\mathrm{B}$ & Inferior $(\operatorname{Exp} b)$ & Exp b & Superior (Exp b) & Sig \\
\hline Incluído & & & & & \\
\hline $\begin{array}{l}\text { Liderança } \\
\text { Transformadora }\end{array}$ & -0538 & 0,347 & 0,584 & 0,984 & 0,043 \\
\hline Constante & 1,131 & & 3,100 & & 0,000 \\
\hline
\end{tabular}

A hipótese H3 (9a regressão): “A presença de modos de inovação e capacidades de inovação aumentam a probabilidade de ocorrência na entrega e/ou qualidade dos serviços.", não foi verificada, sendo que a capacidade liderança transformadora diminui a chance de ocorrência da melhoria na entrega e/ou qualidade dos serviços.

A capacidade de inovação liderança transformadora apresentou um Exp b de 0,584, ou seja, menor que 1 , o que indica que contribuiu negativamente para a melhoria na entrega e/ ou qualidade dos serviços. Como já foi explanado isso não significa que a liderança 
transformadora representa uma barreira à inovação, pelo contrário existe uma fase de adaptação a nova capacidade que num primeiro momento pode apresentar um decréscimo no resultado (Bloch, 2011).

A tabela 11 apresenta os resultados significativos da hipótese $\mathrm{H} 3$ (10 ${ }^{\mathrm{a}}$ regressão), as relações significativas ocorreram com as capacidades de gestão de tecnologia e gestão de projetos.

Tabela 11 - A presença de modos de inovação e capacidades de inovação aumentam a probabilidade de ocorrência de gestão organizacional $\left(10^{\mathrm{a}}\right.$ regressão).

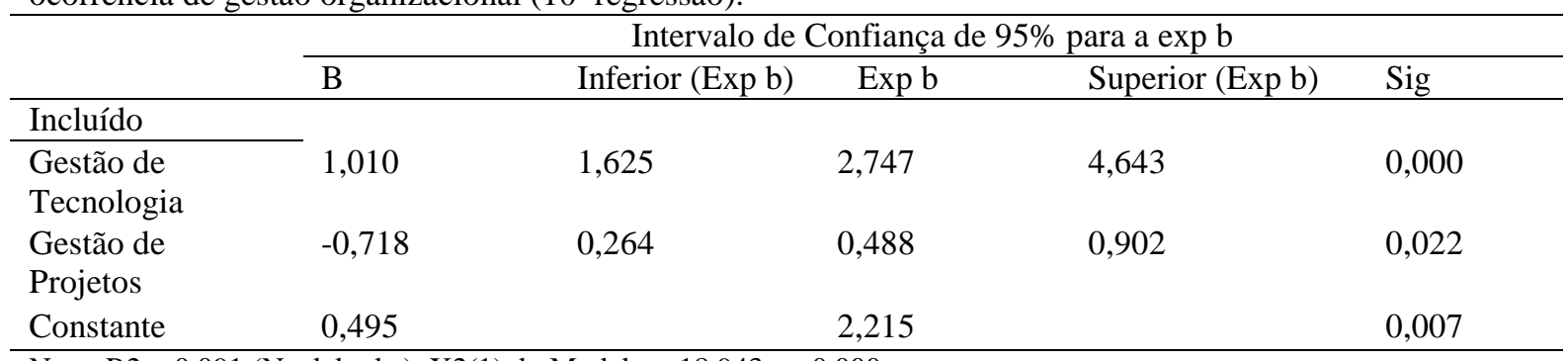

Nota: R2 = 0,091 (Naglekerke). X2(1) do Modelo = 18,943, p<0,000

Fonte: Elaborado pelo autor

A hipótese H3 (10 regressão): “A presença de modos de inovação e capacidades de inovação aumentam a probabilidade de ocorrência de melhoria na Gestão Organizacional”. A presença da capacidade gestão de tecnologia aumenta a probabilidade de ocorrência de melhoria na ocorrência de gestão organizacional, sendo que a capacidade gestão de projetos diminui a chance de ocorrência da melhoria na gestão organizacional. Desta forma, a hipótese foi verificada parcialmente.

A capacidade de inovação gestão de tecnologia apresentou um Exp b de 2,747, o que apresenta uma relação positiva com a ocorrência de gestão organizacional. Por outro lado, a capacidade gestão de projetos apresentou um Exp de 0,488, o que indica uma relação negativa com a melhoria da gestão organizacional.

A tabela 12 apresenta os resultados significativos da hipótese $\mathrm{H} 3$ (11 ${ }^{\mathrm{a}}$ regressão), as relações significativas ocorreram com as capacidades intenção estratégica e gestão de tecnologia.

Tabela 12 - A presença de modos de inovação e capacidades de inovação aumentam a probabilidade de ocorrência de clima organizacional $\left(11^{\mathrm{a}}\right.$ regressão).

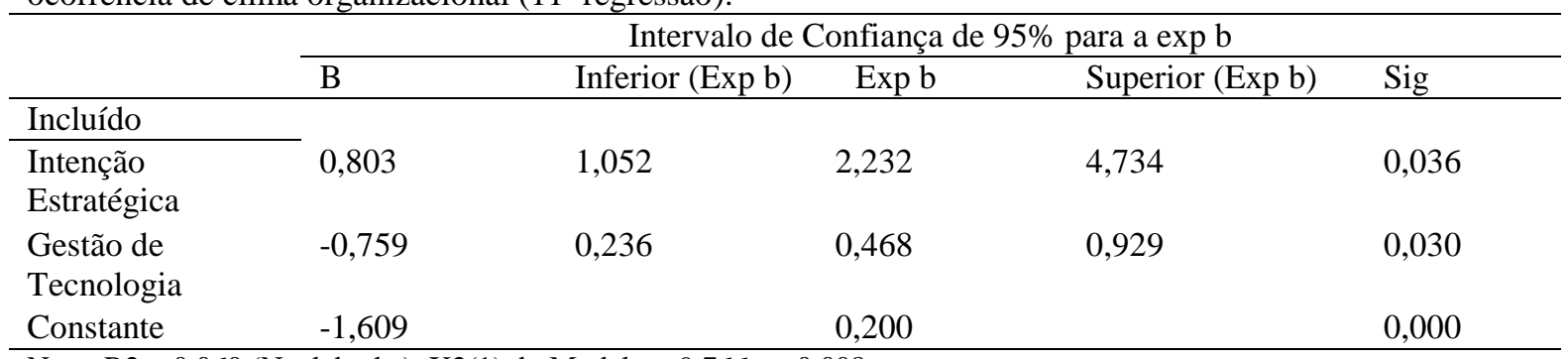

Nota: R2 = 0,060 (Naglekerke). X2(1) do Modelo = 9,766, p<0,008

Fonte: Elaborado pelo autor 
A hipótese H3 (11 a regressão): “A presença de modos de inovação e capacidades de inovação aumentam a probabilidade de ocorrência de melhoria do Clima Organizacional". A presença da capacidade intenção estratégica aumenta a probabilidade de ocorrência de melhoria no clima organizacional, sendo que a capacidade gestão de tecnologia diminui a chance de ocorrência da melhoria no clima organizacional. Desta forma, a hipótese foi verificada parcialmente.

A capacidade de inovação intenção estratégica apresentou um Exp b de 2,232, o que apresenta uma relação positiva com a ocorrência de melhoria no clima organizacional. Por outro lado, a capacidade gestão de tecnologia apresentou um Exp b de 0,468, o que indica uma relação negativa com a melhoria do clima organizacional.

A intenção estratégica apresentou o Exp b superior a 1, isto significa, que quanto mais o previsor (gestão de tecnologia) aumenta a saída (inovação incremental) aumenta, ou seja, são diretamente proporcionais. Assim, a chance de ocorrer uma melhoria de clima organizacional é de aproximadamente 2,2 vezes maior quanto existe a capacidade de inovação estratégica.

A figura 10 apresenta as relações significativas da hipótese $\mathrm{H} 3$, sendo que a linha contínua representa que o Exp b é maior que 1 e a linha tracejada significa que o Exp é menor que 1. É possível ver qual capacidade ou modo e a relação com o resultado. 


\section{Modos + Capacidades}

\section{Resultados}

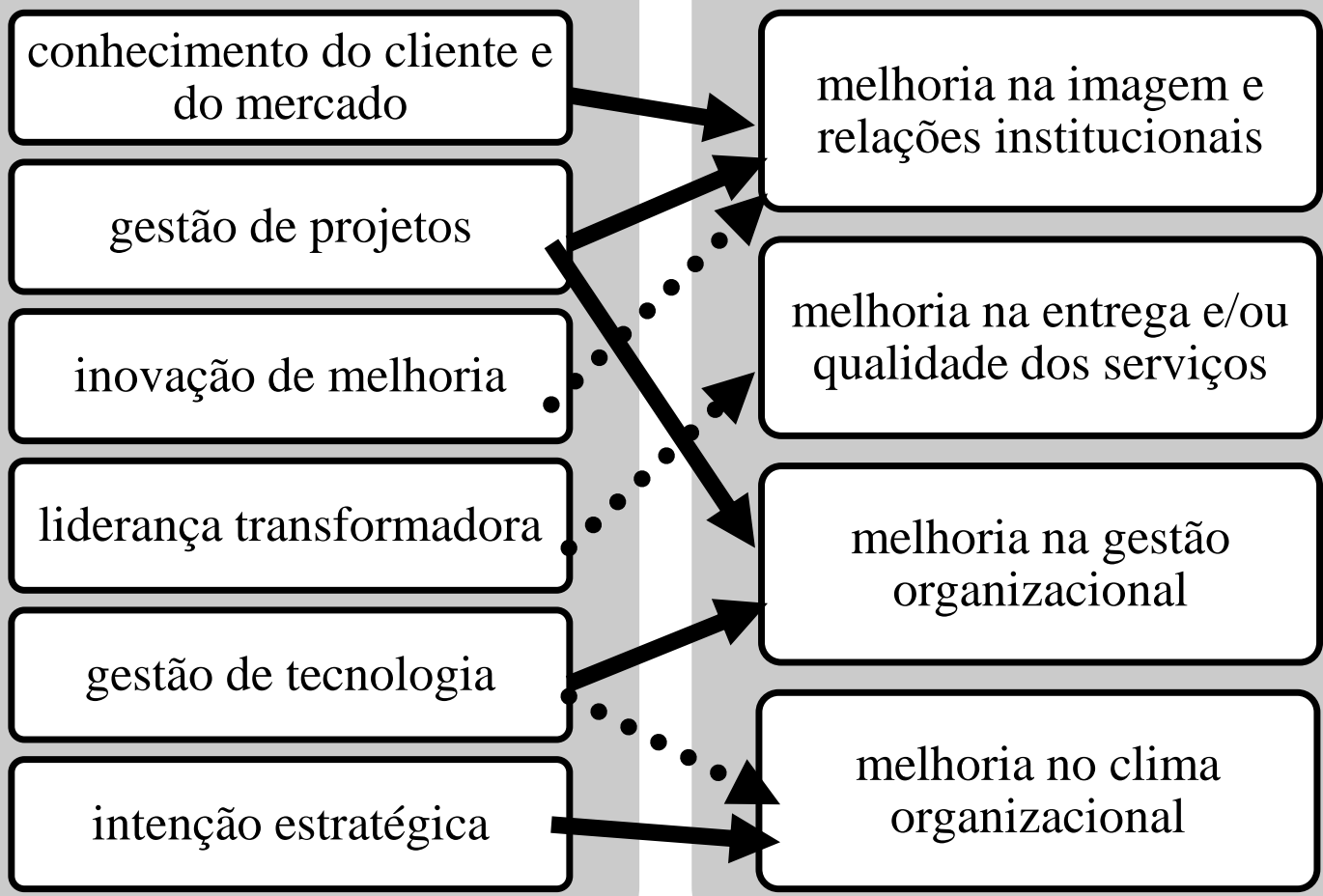

Figura 10 - Relações significativas H3

Fonte: Elaborado pelo Autor

As relações em $\mathrm{H} 3$ foram as mais significativas, pois foram identificadas 5 (cinco) capacidades e 1 (um) modo de inovação que influenciaram os resultados. Algumas relações não foram as esperadas: (i) inovações de melhoria com melhoria na imagem e relações institucionais; (ii) liderança transformadora com melhoria na entrega e/ou qualidade dos serviços e (iii) gestão de tecnologia com melhoria no clima organizacional, pois representaram categorias que diminuíram a chance de ocorrência dos resultados, ou seja, contrário ao modelo proposto.

Isto por si só não invalida o modelo proposto, posto que as inovações para serem implementadas exigem esforço e tempo, sendo que inicialmente pode existir até uma perda de produtividade por causa do esforço inovativo (De Vries et al., 2016). Além disso, nem todas 
as variáveis estão relacionadas no modelo, como barreira e facilitadores, o que poderia ampliar a verificação das relações.

No que tange as relações que aumentaram a chance do resultado ocorrer que foram: (i) conhecimento do usuário com melhoria na imagem de relações institucionais; (ii) gestão de projetos com melhoria na imagem e relações institucionais; (iii) gestão de projetos com melhoria na gestão organizacional; (iv) gestão de tecnologia com melhoria na gestão organizacional e (v) intenção estratégica com melhoria no clima organizacional. Essas relações confirmam o que estava previsto no modelo proposto. As capacidades de inovação são essenciais para o resultado de inovação (Hughes et al., 2011).

Por fim, o Quadro 6 apresenta um cruzamento de informações entre a Tabela 5 e a Figura 10

\begin{tabular}{|c|c|c|c|}
\hline Capacidade & $\mathrm{N}^{\circ}$ de Casos & Percentual (\%) Base 286 & $\begin{array}{c}\text { Aumentou a probabilidade } \\
\text { de resultado }\end{array}$ \\
\hline $\begin{array}{c}\text { Gestão de pessoas para } \\
\text { inovação }\end{array}$ & 216 & 75,5 & Não \\
\hline $\begin{array}{c}\text { Gestão de projetos } \\
\text { Gestão estratégica da } \\
\text { tecnologia }\end{array}$ & 171 & 59,8 & Sim/Não \\
\hline Liderança transformadora & 163 & 57,0 & Não \\
\hline $\begin{array}{c}\text { Organicidade da estrutura } \\
\text { organizacional }\end{array}$ & 154 & 53,8 & Sim \\
\hline Conhecimento do cliente e do \\
mercado
\end{tabular}

Quadro 6 - Cruzamento de informações entre frequências de capacidades e resultado de H3.

Fonte: Elaborado pelo autor

Apesar da gestão de pessoas para inovação ser a capacidade com maior frequência ela não apresentou nenhuma relação significativa com nenhum resultado, sendo que a capacidade com menor frequência que é intenção estratégica de inovar apresentou uma relação positiva com resultados de inovação. O Quadro 6 serve para ressaltar que não se pode concluir somente com base em estatística descritiva, sendo fundamental aprofundar a investigação.

Por meio da regressão logística evidenciou-se que apesar da gestão de pessoas para inovação ser a capacidade com maior frequência ela não possui nenhuma influência no 
resultado. Desta forma, a investigação com outros métodos permitiu uma análise mais eficiente das capacidades de inovação, que pode beneficiar os gestores públicos na tomada de decisão, pois a decisão com base em estatística descritiva pode não atender as expectativas.

A estatística descritiva apesar de ser um método mais simples de ser operacionalizado não pode ser utilizado para realizar inferências, o Quadro 6 é ilustrativo para comparar as capacidades que realmente influenciaram os resultados, por exemplo, a capacidade liderança transformadora que tem elevada frequência não teve uma relação positiva com os resultados da inovação. 


\section{Conclusão}

Este trabalho buscou analisar o efeito dos modos de inovação nos resultados da inovação, das capacidades de inovação nos modos de inovação e modos de inovação com capacidades de inovação nos resultados. Como não existe modelo de inovação para o setor público brasileiro foram investigados outros modelos de inovação para a elaboração do modelo proposto.

O modelo proposto para verificação dos efeitos foi elaborado a partir da verificação de modelos internacionais de mensuração de inovação para o setor público, destacando o modelo do NESTA (National Endowement for Science Technology and the Arts), do Reino Unido e de artigos internacionais e nacionais sobre o tema.

Os dados para este trabalho foram coletados a partir da análise de 286 casos premiados do Concurso de Inovação da ENAP entre os anos 1999 e 2014. Os relatos das experiências premiadas passaram por uma análise de conteúdo que foram devidamente inseridas no banco de dados Innovapublic, que foi construído por meio da triangulação de pesquisadores para aumentar a confiabilidade das informações, sendo a triangulação uma técnica utilizada para mitigar os riscos durante o processo de análise. Os dados foram codificados por meio de uma variável binária, sendo que o número 1 indica a presença de determinada característica, sendo que o número 0 indica a ausência de determinada característica.

A construção da base de dados foi efetuada análise utilizando estatísticas descritivas e inferenciais. A estatística descritiva apresentou as frequências das variáveis de interesse, a regressão logística foi utilizada devido à natureza da variável de saída, que foi codificada como dicotômica (binária). Ela é a regressão recomendada para o caso, pois os pressupostos de linearidade geralmente são violados quando a variável de saída é binária.

A conclusão das hipóteses deste estudo podem ser observadas no Quadro 7. São 3 (três) hipóteses que foram operacionalizadas em 11 (onze) regressões logísticas para facilitar a utilização do software SPSS. É importante esclarecer que o conceito o do termo "não verificada" no Quadro 7 significa que a hipótese foi testada e não verificada. 


\begin{tabular}{|c|c|c|}
\hline Identificação & Descrição & Verificação \\
\hline H1 & $\begin{array}{l}\text { A presença de modos de inovação aumenta a probabilidade de } \\
\text { ocorrência de resultados da inovação. }\end{array}$ & Não verificada \\
\hline $1^{\mathrm{a}}$ regressão & $\begin{array}{l}\text { A presença de modos de inovação aumenta a probabilidade de ocorrência } \\
\text { de inovação na imagem e relações institucionais. }\end{array}$ & Não verificada* \\
\hline $2^{\mathrm{a}}$ regressão & $\begin{array}{l}\text { A presença de modos de inovação aumenta a probabilidade de ocorrência } \\
\text { na entrega e/ou qualidade dos serviços. }\end{array}$ & Não verificada \\
\hline $3^{\mathrm{a}}$ regressão & $\begin{array}{l}\text { A presença de modos de inovação aumenta a probabilidade de ocorrência } \\
\text { de Gestão Organizacional. }\end{array}$ & Não verificada \\
\hline $4^{\mathrm{a}}$ regressão & $\begin{array}{l}\text { A presença de modos de inovação aumenta a probabilidade de ocorrência } \\
\text { de Clima Organizacional. }\end{array}$ & Não verificada \\
\hline $\mathrm{H} 2$ & $\begin{array}{l}\text { A presença de capacidade de inovação aumenta a probabilidade de } \\
\text { modos de inovação }\end{array}$ & $\begin{array}{l}\text { Verificada } \\
\text { parcialmente }\end{array}$ \\
\hline $5^{\mathrm{a}}$ regressão & $\begin{array}{l}\text { A presença de capacidade de inovação aumenta a probabilidade de uma } \\
\text { inovação radical }\end{array}$ & Não verificada \\
\hline $6^{\mathrm{a}}$ regressão & $\begin{array}{l}\text { A presença de capacidade de inovação aumenta a probabilidade de uma } \\
\text { inovação de melhoria }\end{array}$ & Não verificada \\
\hline $7^{\mathrm{a}}$ regressão & $\begin{array}{l}\text { A presença de capacidade de inovação aumenta a probabilidade de uma } \\
\text { inovação incremental }\end{array}$ & Verificada \\
\hline $\mathrm{H} 3$ & $\begin{array}{l}\text { A presença de modos de inovação e capacidades de inovação } \\
\text { aumentam a probabilidade de ocorrência de resultados da inovação. }\end{array}$ & $\begin{array}{l}\text { Verificada } \\
\text { parcialmente }\end{array}$ \\
\hline $8^{\mathrm{a}}$ regressão & $\begin{array}{l}\text { A presença de modos de inovação e capacidades de inovação aumentam a } \\
\text { probabilidade de ocorrência de inovação na imagem e relações } \\
\text { institucionais. }\end{array}$ & $\begin{array}{l}\text { Verificada } \\
\text { parcialmente* }\end{array}$ \\
\hline $9^{a}$ regressão & $\begin{array}{l}\text { A presença de modos de inovação e capacidades de inovação aumentam a } \\
\text { probabilidade de ocorrência na entrega e/ou qualidade dos serviços. }\end{array}$ & Não Verificada* \\
\hline $10^{\mathrm{a}}$ regressão & $\begin{array}{l}\text { A presença de modos de inovação e capacidades de inovação aumentam a } \\
\text { probabilidade de ocorrência de Gestão Organizacional. }\end{array}$ & $\begin{array}{l}\text { Verificada } \\
\text { parcialmente* }\end{array}$ \\
\hline $11^{\mathrm{a}}$ regressão & $\begin{array}{l}\text { A presença de modos de inovação e capacidades de inovação aumentam a } \\
\text { probabilidade de ocorrência de Clima Organizacional. }\end{array}$ & $\begin{array}{l}\text { Verificada } \\
\text { parcialmente* }\end{array}$ \\
\hline
\end{tabular}

*apresentou relação contrária a inicialmente proposta

Quadro 7 - Resultados das hipóteses do estudo

Fonte: Elaborado pelo autor

As hipóteses que não foram verificadas ou quando foram verificadas apresentaram resultados opostos ao esperado não invalidam o modelo, posto que existem diversos tipos de etapas no processo de inovação. Já foi ressaltado que a implementação de inovação pode no primeiro momento prejudicar o resultado, após um período de amadurecimento a inovação tende a produzir uma melhoria nos resultados (Bloch, 2011).

As outras hipóteses foram verificadas e confirmaram o esperado pelo modelo proposto, ou seja, o aumento da probabilidade da ocorrência do resultado. Assim, as capacidades e os modos de inovação influenciaram positivamente a ocorrência do resultado de inovação.

O trabalho apresentou contribuições metodológicas e empíricas. As contribuições empíricas estão representadas nas capacidades e modos de inovação que influenciaram nos resultados de inovação, podendo servir como uma orientação para os gestores públicos em 
relação a tomada de decisão em relação às capacidades de inovação. Como contribuição metodológica este estudo apresentou um possível modelo que poderá subsidiar pesquisas futuras para a elaboração de um modelo de inovação do setor público brasileiro.

Uma das limitações deste trabalho está atrelada a utilização de dados secundários que não permitem a elaboração de um instrumento de pesquisa com uma maior intervenção do pesquisador sobre o tema, pois existem limitações nos relatos. Os relatos não foram concebidos para esta pesquisa e podem limitar os resultados deste estudo. A base de dados analisada compreende as iniciativas que foram submetidas e classificadas no período de 1999 a 2014, contudo outras experiências frutíferas no Poder Executivo Federal podem não ter atendido algum requisito da submissão e apesar de serem importantes na contribuição de inovação no setor público não foram analisadas.

A codificação em variáveis binárias (presença ou ausência) pode representar uma limitação na análise, pois o principal método inferencial utilizado foi à regressão logística que tem como variável de saída o aumento/diminuição da razão de probabilidade, outros métodos com variáveis escalares poderiam ser mais conclusivos. O recorte desta pesquisa que subdividiu os modos de inovação em três tipos (melhoria, incremental e radical), capacidades de inovação em sete tipos (gestão de pessoas para inovação, gestão de projetos, gestão estratégica da tecnologia, liderança transformadora, organicidade da estrutura organizacional, conhecimento do cliente e intenção estratégica de inovar) e resultados de inovação em quatro tipos (melhoria na gestão organizacional, melhoria na entrega e/ou qualidade dos serviços, melhoria na imagem e relações institucionais e melhoria no clima organizacional), gera também uma limitação na pesquisa, pois essas variáveis podem ser classificadas de outras formas.

Como pesquisas futuras podem ser verificadas novas relações no banco de dados, incluindo facilitadores e barreiras de inovação. Novas informações podem ser acrescidas ao banco de dados replicando a mesma técnica de análise de conteúdo para expandir para outros concursos de inovação, como por exemplo, o Innovare ou Concurso da RFB, que permitiria um alcance maior das experiências inovadoras na gestão pública. Outros construtos incluindo coprodução, governança da inovação podem configurar um tópico a ser pesquisado. A utilização de dados primários, como por exemplo, coletados por meio de questionários, poderiam contribuir para uma pesquisa mais profunda sobre o tema. 


\section{Referências}

Albuquerque, E. D. M. E. (1996). Sistema nacional de inovação no Brasil: uma análise introdutória a partir de dados disponíveis sobre a ciência e a tecnologia. Revista de Economia Política.

Albury, D. (2005). Fostering innovation in public services. Public Money and Management.

Bardin, L. (2011). ANALISE DE CONTEUDO (1 ${ }^{\mathrm{a}}$ edição). São Paulo: Edições 70.

Bloch, C. (2011). Measuring Public Innovation in the Nordic Countries ( MEPIN ) Participants :, (February).

Bugge, M., Mortensen, P. S., \& Bloch, C. (2011). Report of the Nordic Pilot studies Analyses of methodology and results. Conpenhagen: MEPIN.

Carrijo, M. de C., \& Botelho, M. (2013). Cooperação e inovação: uma análise dos resultados do Programa de Apoio à Pesquisa em Empresas (Pappe). Revista Brasileira de Inovação.

Costa, J. O. P. da, Mendonça, S., \& Campos, A. S. (2015). The Entrepreneurial State:

Debunking Public vs Private Sector Myths. Revista Brasileira de Inovação, 14, 203-208. https://doi.org/10.1093/scipol/scu071

De Vries, H., Bekkers, V., \& Tummers, L. (2016). Innovation in the public sector: A systematic review and future research agenda. Public Administration, 94(1), 146-166. https://doi.org/10.1111/padm.12209

Di Pietro, M. S. Z. (2005). Direito Administrativo (18 ). São Paulo: Atlas.

Djellal, F., \& Gallouj, F. (2007). Innovation in hospitals: A survey of the literature. European Journal of Health Economics, 8(3), 181-193. https://doi.org/10.1007/s10198-006-0016-3

Djellal, F., Gallouj, F., \& Miles, I. (2013). Two decades of research on innovation in services: Which place for public services? Structural Change and Economic Dynamics, 27, 98117. https://doi.org/10.1016/j.strueco.2013.06.005 
Eggers, W. D., \& Singh, S. K. (2009). The Public Innovator 's Playbook: Nurturing bold ideas in government.

Enap, E. N. de A. P. (2016). Enap. Retrieved May 24, 2016, from http://inovacao.enap.gov.br/ Esaf, E. de A. F. (2016). Esaf. Retrieved from http://www.esaf.fazenda.gov.br/assuntos/premios

Field, A. (2013). Discovering Statistics using IBM SPSS Statistics. Sage.

Flick, U. (2009). An introduction to qualitative research. London: SAGE.

Fontenelle, I. a. (2012). Para uma crítica ao discurso da inovação: saber e controle no capitalismo do conhecimento. Revista de Administração de Empresas, 52(1), 100-109. https://doi.org/10.1590/S0034-75902012000100008

Gadrey, J., Gallouj, F., \& Weinstein, O. (1995). New modes of innovation: How services benefit industry. International Journal of Service Industry Management, 6(3), 4-16. https://doi.org/10.1108/09564239510091321

Gallouj, F. (2002). Innovation in services and the attendant old and new myths. Journal of Socio-Economics, 31(2), 137-154. https://doi.org/10.1016/S1053-5357(01)00126-3

Gallouj, F., \& Savona, M. (2009). Innovation in services: A review of the debate and a research agenda. Journal of Evolutionary Economics, 19(2), 149-172. https://doi.org/10.1007/s00191-008-0126-4

Gallouj, F., \& Savona, M. (2010). Towards a theory of innovation in services: a state of the art. The Handbook of Innovation and Services: A Multi-Disciplinary Perspective, 27-48.

Gil, A. C. (2008). Métodos e técnicas de pesquisa social (6 $6^{\mathrm{a}}$ ). São Paulo: Atlas.

Hair, J., Babin, B., Money, A., \& Samouel, P. (2005). Fundamentos de métodos de pesquisa em administração. Porto Alegre: Bookman.

Halvorsen, T., Hauknes, J., Miles, I., \& Roste, R. (2005). On the differences between public and private sector innovation. Innovation in the Public Sector, 1998-2002. 
https://doi.org/10.1057/9780230307520

Hauknes, J. (1998). Services in innovation - innovation in services, (August), 101.

Higgins, J. M. (1995). Innovate or evaporate : test \&amp; improve your organization's I.Q., its innovation quotient. New Management Pub. Co.

Hill, T. P. (1977). On goods and services. Review of Income \& Wealth, 23(4), 315-338. https://doi.org/10.1111/j.1475-4991.1977.tb00021.x

Hughes, A., Moore, K., \& Kataria, N. (2011). Innovation in Public Sector Organisations: A pilot survey for measuring innovation across the public sector. NESTA Index Report, (March), 1-85.

Innovare, I. I. (2016). Prêmio Innovare.

InnovationUnit. (2009). an Innovation Index for the Public Sector. Image (Rochester, N.Y.), Final Draf(October), 1-26.

Kato, E. M., Gobara, C., Rossoni, L., \& Cunha, S. K. (2008). PADRÕES DE COOPERAÇÃO TECNOLÓGICA ENTRE SETORES NA INDÚSTRIA BRASILEIRA: UMA ANÁLISE QUANTITATIVA DOS DADOS DA PINTEC 20012003. Revista de Administração E Inovação - RAI, 128-142.

Kattel, R., Cepilovs, A., Drechsler, W., Kalvet, T., Lember, V., \& Tonurist, P. (2014). Can we measure public sector innovation? A literature review. LIPSE Working Papers, (2), 2 38.

Koc, T. (2007). Organizational determinants of innovation capacity in software companies. Computers \& Industrial Engineering.

Koch, P., \& Hauknes, J. (2005). On innovation in the public sector.

Kubota, L. C. (2009). As Kibs e a inovação tecnológica das firmas de serviços. Economia E Sociedade, 18(2), 349-369. https://doi.org/10.1590/S0104-06182009000200005

Kuhlmann, S. (2010). Performance Measurement in European local governments: a 
comparative analysis of reform experiences in Great Britain, France, Sweden and Germany. International Review of Administrative Sciences, 76(2), 331-345. https://doi.org/10.1177/0020852310372050

Lam, A. (2005). Organizational Innovation. (Chapter 5). In Fagerberg, J., Mowery, D. \& Nelson, R.R. (Orgs.),. In The Oxford Handbook of Innovation. Oxford: Oxford University Press.

Lawson, B., \& Samson, D. (2001). Developing innovation capability in organisations: a dynamic capabilities approach. International Journal of Innovation.

Leite, A. C. C. (2013). Investimentos em P\&D no Brasil e na China: uma questão de estrutura. Boletim Meridiano, 13, 13-20.

Levitt, T. (1990). A Imaginação de Marketing (2 $\left.{ }^{\mathrm{a}}\right)$. São Paulo: Atlas.

Malhotra, N. (2012). Pesquisa de marketing: uma orientação aplicada (6 $\left.{ }^{\mathrm{a}}\right)$. Porto Alegre: Bookman.

Marconi, M., \& Lakatos, E. (2010). Fundamentos de metodologia científica. Fundamentos de metodologia científica $\left(7^{\mathrm{a}}\right)$. São Paulo: Atlas.

Morettin, L. . (2010). Morettin, L. G. (2010). Estatística básica: probabilidade e inferência: volume único. São Paulo: Pearson Prentice Hall. - Google Acadêmico. São Paulo: Pearson Prentice Hall.

Mulgan, G. (2014). Innovation in the Public Sector How Can Public Organisations Better Create, Improve and Adapt? Nesta, 1(November), 1-20.

Mustafid, Q., \& Anggadwita, G. (2013). Determining innovation aspect in the performance of public service sector. Journal of Social and.

Nelson, R., \& Winter, S. (2005). Uma Teoria Evolucionária da Mudança Econômica. Campinas: Unicamp.

Newcomer, K., \& Allen, H. (2010). Public service education: Adding value in the public 
interest. Journal of Public Affairs Education.

OECD. (2005). Manual de Oslo: Diretrizes para a Coleta e Interpretação de dados sobre Inovação Tecnológica. OCDE, Eurostat E Financiadora de Estudos E Projetos, 184. https://doi.org/10.1787/9789264065659-es

Peng, D., Schroeder, R., \& Shah, R. (2008). Linking routines to operations capabilities: A new perspective. Journal of Operations Management.

Potts, J., \& Kastelle, T. (2010). Public sector innovation research: What's next? Innovation. Salerno, M. ., \& Kubota, L. . (2008). Estado e Inovação. In: De Negri, J. A. \& Kubota, L. C. (Org.). Políticas de incentivo à inovação tecnológica no Brasil. IPEA, 13-64.

Saviotti, P., \& Metcalfe, J. (1984). A theoretical approach to the construction of technological output indicators. Research Policy.

Tidd, J., Bessant, J., \& Pavitt, K. (2008). Gestão da Inovação (3ª). Porto Alegre: Bookman.

Tigre, P. B. (2006). Gestão da Inovação - A economia da tecnologia no Brasil. Rio de Janeiro: Elsevier.

Valladares, P. S. D. de A., Vasconcellos, M. A. de, \& Serio, L. C. Di. (2014). Capacidade de Inovação: Revisão Sistemática da Literatura. Revista de Administração Contemporânea, 18(5), 598-626. https://doi.org/10.1590/1982-7849rac20141210

Yen, H. R., Wang, W., Wei, C. P., Hsu, S. H. Y., \& Chiu, H. C. (2012). Service innovation readiness: Dimensions and performance outcome. Decision Support Systems, 53(4), 813824. https://doi.org/10.1016/j.dss.2012.05.015 


\section{Anexos}

Anexo A - Protocolo de coleta e codificação de informações

\begin{tabular}{|c|c|c|c|}
\hline \multicolumn{4}{|c|}{ Modos de inovação } \\
\hline Categorias & Definição & Forma de identificação & Palavras-chave \\
\hline Inovação radical & $\begin{array}{c}\text { Criação de um produto } \\
\text { totalmente novo; } \\
\text { descreve a criação de um } \\
\text { novo conjunto de } \\
\text { características } \mathrm{S}=\left\{\left[\mathrm{C}^{*}\right],\right. \\
\left.\left[\mathrm{C}^{*}\right],\left[\mathrm{X}^{*}\right],\left[\mathrm{X}^{*}\right],\left[\mathrm{Y}^{*}\right]\right\}\end{array}$ & $\begin{array}{l}\text { Detecção de serviços que } \\
\text { não se relacionam com o } \\
\text { sistema antigo }\left\{[\mathrm{C}],\left[\mathrm{C}^{\prime}\right]\right. \\
\left.[\mathrm{X}],\left[\mathrm{X}^{\prime}\right],[\mathrm{Y}]\right\} \text { da } \\
\text { organização. }\end{array}$ & $\begin{array}{l}\text { Novo; novidade; inédito; } \\
\text { diferente. }\end{array}$ \\
\hline Inovação de melhoria & $\begin{array}{l}\text { Melhoramento de certas } \\
\text { características sem } \\
\text { alteração do sistema }\end{array}$ & $\begin{array}{c}\text { Detecção de serviços com } \\
\text { características [Y] } \\
\text { melhoradas como reflexo } \\
\text { do melhoramento de } \\
\text { competências }[\mathrm{C}] \mathrm{e} \\
\text { características técnicas } \\
{[\mathrm{X}]}\end{array}$ & $\begin{array}{l}\text { Melhoramento; } \\
\text { otimização. }\end{array}$ \\
\hline Inovação incremental & $\begin{array}{c}\text { Mudança marginal no } \\
\text { sistema através de novos } \\
\text { elementos adicionados } \\
\text { para }[\mathrm{X}],\left[\mathrm{X}^{\prime}\right] \text { e/ou }[\mathrm{Y}] \\
\text { ou pela substituição dos } \\
\text { mesmos }\end{array}$ & $\begin{array}{c}\text { Detecção de serviços com } \\
\text { adição de ou substituição } \\
\text { de características finais } \\
\text { [Y] e/ou características } \\
\text { técnicas }[\mathrm{X}]\end{array}$ & $\begin{array}{l}\text { Implementação; adição; } \\
\text { troca ou substituição de } \\
\text { elementos. }\end{array}$ \\
\hline
\end{tabular}

\begin{tabular}{|c|c|c|c|}
\hline \multicolumn{4}{|c|}{ Capacidade de inovação } \\
\hline Categorias & Definição & Forma de identificação & Palavras-chave \\
\hline Liderança transformadora & $\begin{array}{l}\text { Aquela que torna seus } \\
\text { seguidores mais } \\
\text { conscientes da } \\
\text { importância e do valor do } \\
\text { trabalho, ativa suas } \\
\text { necessidades de ordem } \\
\text { superior, e os induz a } \\
\text { transcender seus } \\
\text { interesses pessoais em } \\
\text { prol da organização. }\end{array}$ & $\begin{array}{l}\text { Detecção de práticas que } \\
\text { indicam a atuação } \\
\text { determinante de líderes, } \\
\text { com a capacidade de } \\
\text { mobilizar a equipe em } \\
\text { prol dos objetivos } \\
\text { organizacionais. }\end{array}$ & $\begin{array}{l}\text { Apoio da alta gestão, } \\
\text { liderança, habilidade de } \\
\text { comunicação, disposição } \\
\text { para assumir riscos, } \\
\text { reconhecimento de } \\
\text { desempenho, } \\
\text { comunicação da visão de } \\
\text { futuro, rede de } \\
\text { relacionamento, } \\
\text { comprometimento, gestão } \\
\text { de inovação e melhoria. }\end{array}$ \\
\hline $\begin{array}{c}\text { Intenção estratégica de } \\
\text { inovar }\end{array}$ & $\begin{array}{c}\text { Grau que a organização } \\
\text { está disposta a assumir } \\
\text { riscos para favorecer a } \\
\text { mudança, o } \\
\text { desenvolvimento } \\
\text { tecnológico e a inovação, } \\
\text { estabelecendo-os por } \\
\text { meio de sua estratégia. }\end{array}$ & $\begin{array}{c}\text { Detecção de práticas que } \\
\text { apontam para inserção da } \\
\text { inovação na estratégia } \\
\text { organizacional. }\end{array}$ & $\begin{array}{c}\text { Consenso sobre } \\
\text { importância da inovação, } \\
\text { plano estratégico inclui } \\
\text { inovação, metas } \\
\text { desafiadoras, métricas e } \\
\text { projetos de inovação. }\end{array}$ \\
\hline $\begin{array}{l}\text { Gestão de pessoas para } \\
\text { inovação }\end{array}$ & $\begin{array}{l}\text { Orientação da gestão de } \\
\text { pessoas para a inovação, } \\
\text { provendo a concessão de } \\
\text { liberdade ou autonomia }\end{array}$ & $\begin{array}{c}\text { Detecção de práticas que } \\
\text { demonstram } \\
\text { direcionamento da gestão } \\
\text { de pessoas para inovação. }\end{array}$ & $\begin{array}{l}\text { Criatividade, trabalho } \\
\text { desafiador, treinamento e } \\
\text { desenvolvimento, solução } \\
\text { de problemas, busca do }\end{array}$ \\
\hline
\end{tabular}




\begin{tabular}{|c|c|c|c|}
\hline & $\begin{array}{c}\text { de atuação aos } \\
\text { empregados, } \\
\text { estabelecendo metas } \\
\text { desafiadoras, permitindo } \\
\text { que decidam como } \\
\text { alcançá-las e favorecendo } \\
\text { a autorrealização e o } \\
\text { comprometimento com } \\
\text { os objetivos da } \\
\text { organização. }\end{array}$ & & $\begin{array}{l}\text { conhecimento, } \\
\text { recompensa, ambiente } \\
\text { propício. }\end{array}$ \\
\hline $\begin{array}{l}\text { Conhecimento do usuário } \\
\text { e do ambiente }\end{array}$ & $\begin{array}{l}\text { Habilidade para detectar } \\
\text { os eventos, necessidades, } \\
\text { expectativas, mudanças } \\
\text { significativas e } \\
\text { tendências dos usuários e } \\
\text { do ambiente. }\end{array}$ & $\begin{array}{l}\text { Detecção de práticas que } \\
\text { indicam o esforço para } \\
\text { conhecimento interno } \\
\text { sobre cliente e mercado }\end{array}$ & $\begin{array}{c}\text { Identificação de } \\
\text { oportunidade de } \\
\text { melhoria, trabalho } \\
\text { conjunto com clientes, } \\
\text { conhecimento de } \\
\text { mercado, compreensão } \\
\text { das necessidades dos } \\
\text { clientes. }\end{array}$ \\
\hline $\begin{array}{l}\text { Gestão estratégica da } \\
\text { tecnologia }\end{array}$ & $\begin{array}{l}\text { Gestão do processo de } \\
\text { criação e } \\
\text { desenvolvimento de } \\
\text { tecnologias, visando à } \\
\text { criação de valor. O } \\
\text { processo de gestão } \\
\text { tecnológica compreende } \\
\text { cinco etapas: } \\
\text { identificação, seleção, } \\
\text { aquisição, exploração e } \\
\text { proteção. }\end{array}$ & $\begin{array}{l}\text { Detecção de práticas de } \\
\text { gestão de tecnologia } \\
\text { integrada à estratégia da } \\
\text { organização. }\end{array}$ & $\begin{array}{c}\text { Gestão tecnológica, } \\
\text { desenvolvimento de } \\
\text { sistemas, infraestrutura } \\
\text { tecnológica, aquisição de } \\
\text { tecnologia. }\end{array}$ \\
\hline $\begin{array}{c}\text { Organicidade da estrutura } \\
\text { organizacional }\end{array}$ & $\begin{array}{l}\text { Grau em que a estrutura é } \\
\text { caracterizada pela } \\
\text { concessão de autonomia, } \\
\text { controles flexíveis, } \\
\text { comunicação horizontal } \\
\text { desimpedida, valorização } \\
\text { do conhecimento e da } \\
\text { experiência e } \\
\text { informalidade nas } \\
\text { relações pessoais. } \\
\text { Estruturas ditas orgânicas } \\
\text { permitem resposta mais } \\
\text { rápida às mudanças no } \\
\text { ambiente externo do que } \\
\text { as denominadas } \\
\text { mecanicistas. }\end{array}$ & $\begin{array}{c}\text { Detecção de práticas que } \\
\text { mostram uma estrutura } \\
\text { organizacional orgânica. }\end{array}$ & $\begin{array}{c}\text { Tomada rápida de } \\
\text { decisões, autonomia da } \\
\text { equipe, comunicação } \\
\text { ágil, controle flexível, } \\
\text { equipe diversificada, } \\
\text { interação de diferentes } \\
\text { áreas, autonomia na } \\
\text { resolução de problemas, } \\
\text { colaboração entre } \\
\text { equipes. }\end{array}$ \\
\hline Gestão de projetos & $\begin{array}{c}\text { Planejamento, provisão } \\
\text { dos recursos, execução e } \\
\text { controle do processo de } \\
\text { inovação. Inclui } \\
\text { cuidadosa avaliação dos } \\
\text { projetos, análise e } \\
\text { planejamento visando, } \\
\text { principalmente, ganhar } \\
\text { compreensão, } \\
\text { compromisso e apoio } \\
\text { tanto corporativo quanto } \\
\text { do pessoal que estará } \\
\text { envolvido no projeto. }\end{array}$ & $\begin{array}{c}\text { Detecção de práticas que } \\
\text { visam a gestão do } \\
\text { processo de inovação. }\end{array}$ & $\begin{array}{c}\text { Planejamento, recursos } \\
\text { para inovação, controle, } \\
\text { avaliação, projeto com } \\
\text { apoio de sistemas, } \\
\text { estruturação de projetos, } \\
\text { rapidez na execução do } \\
\text { projeto. }\end{array}$ \\
\hline
\end{tabular}




\begin{tabular}{|c|c|c|c|}
\hline \multicolumn{4}{|c|}{ Resultados de inovação } \\
\hline Categorias & Definição & Forma de identificação & Palavras-chave \\
\hline $\begin{array}{l}\text { Melhoria da imagem e } \\
\text { relações institucionais }\end{array}$ & $\begin{array}{c}\text { Consequências ou } \\
\text { impactos positivos na } \\
\text { imagem da organização e } \\
\text { em suas relações. }\end{array}$ & $\begin{array}{l}\text { Detecção dos impactos } \\
\text { positivos obtidos a partir } \\
\text { da implementação dos } \\
\text { projetos inovadores }\end{array}$ & $\begin{array}{l}\text { Crescimento do prestígio } \\
\text { dos serviços públicos } \\
\text { oferecidos; } \\
\text { accountability; aumento } \\
\text { da ética e transparência } \\
\text { na gestão dos serviços; } \\
\text { respeito e capacidade de } \\
\text { crescimento; } \\
\text { profissionalismo e } \\
\text { expertises das equipes de } \\
\text { trabalho }\end{array}$ \\
\hline $\begin{array}{c}\text { Melhoria na entrega e/ou } \\
\text { qualidade dos serviços }\end{array}$ & $\begin{array}{c}\text { Consequências ou } \\
\text { impactos positivos na } \\
\text { qualidade do serviço e } \\
\text { nas organizações }\end{array}$ & $\begin{array}{l}\text { Detecção dos impactos } \\
\text { positivos obtidos a partir } \\
\text { da implementação dos } \\
\text { projetos inovadores }\end{array}$ & $\begin{array}{l}\text { Melhoramento dos } \\
\text { serviços oferecidos; } \\
\text { eficiência e efetividade } \\
\text { na gestão dos serviços; } \\
\text { maior produtividade das } \\
\text { instituições públicas; } \\
\text { economicidade; } \\
\text { Comprometimento dos } \\
\text { atores envolvidos no } \\
\text { serviço; aumento do } \\
\text { conhecimento, } \\
\text { adaptabilidade e } \\
\text { capacidade de realização }\end{array}$ \\
\hline $\begin{array}{c}\text { Melhoria de gestão } \\
\text { organizacional }\end{array}$ & $\begin{array}{l}\text { Capacidade de lidar com } \\
\text { diversas competências } \\
\text { dos atores da organização } \\
\text { exercendo atividades de } \\
\text { acompanhamento, } \\
\text { controle e avaliação. }\end{array}$ & $\begin{array}{l}\text { Detecção dos impactos } \\
\text { positivos na gestão } \\
\text { organizacional obtidos a } \\
\text { partir da implementação } \\
\text { das práticas inovadoras. }\end{array}$ & $\begin{array}{l}\text { Motivação da força de } \\
\text { trabalho; coordenação e } \\
\text { colaboração efetiva; } \\
\text { maior controle de } \\
\text { gerenciamento; } \\
\text { efetividade na tomada de } \\
\text { decisão; efetividade no } \\
\text { gerenciamento da } \\
\text { comunicaçãa entre } \\
\text { equipes. }\end{array}$ \\
\hline $\begin{array}{c}\text { Melhoria do clima } \\
\text { organizacional }\end{array}$ & $\begin{array}{l}\text { Princípios incorporados } \\
\text { às práticas de gestão e } \\
\text { execução que afetam } \\
\text { todos os atores de uma } \\
\text { organização. }\end{array}$ & $\begin{array}{c}\text { Detecção dos impactos } \\
\text { positivos no clima } \\
\text { organizacional obtidos a } \\
\text { partir da implementação } \\
\text { das práticas inovadoras. }\end{array}$ & $\begin{array}{l}\text { Criação de sistemas de } \\
\text { recompensa; } \\
\text { encorajamento da } \\
\text { criatividade; aumento de } \\
\text { autonomia; recursos } \\
\text { suficientes para } \\
\text { realização das tarefas; } \\
\text { baixa pressão sobre os } \\
\text { colaboradores; suporte à } \\
\text { pesquisa de novas formas } \\
\text { de realizar as tarefas. }\end{array}$ \\
\hline
\end{tabular}


Anexo B - Modelo de quadro para coleta e codificação de informações

\begin{tabular}{|c|c|c|c|}
\hline \multicolumn{4}{|c|}{ Nome da organização } \\
\hline \multicolumn{4}{|c|}{ Ministério de vinculação } \\
\hline \multicolumn{4}{|c|}{ Título da experiência } \\
\hline \multirow{2}{*}{\multicolumn{4}{|c|}{$\begin{array}{c}\text { Caso xxxx } \\
\text { Ano xxxx }\end{array}$}} \\
\hline & & & \\
\hline Tipo de inovação & $\begin{array}{l}\text { Identificado }(0=\text { não; } 1= \\
\text { sim) }\end{array}$ & Trecho do relato & Termo de identificação \\
\hline \multicolumn{4}{|l|}{ Radical } \\
\hline \multicolumn{4}{|l|}{ Melhoria } \\
\hline \multicolumn{4}{|l|}{ Incremental } \\
\hline Capacidade de inovação & $\begin{array}{l}\text { Identificado }(0=\text { não; } 1= \\
\text { sim) }\end{array}$ & Trecho do relato & Termo de identificação \\
\hline \multicolumn{4}{|c|}{ Liderança transformadora } \\
\hline \multicolumn{4}{|l|}{$\begin{array}{l}\text { Intenção estratégica de } \\
\text { inovar }\end{array}$} \\
\hline \multicolumn{4}{|l|}{$\begin{array}{c}\text { Gestão de pessoas para } \\
\text { inovação }\end{array}$} \\
\hline \multicolumn{4}{|l|}{$\begin{array}{l}\text { Conhecimento do usuário } \\
\text { e do ambiente }\end{array}$} \\
\hline \multicolumn{4}{|l|}{$\begin{array}{c}\text { Gestão estratégica da } \\
\text { tecnologia }\end{array}$} \\
\hline \multicolumn{4}{|l|}{$\begin{array}{c}\text { Organicidade da estrutura } \\
\text { organizacional }\end{array}$} \\
\hline \multicolumn{4}{|l|}{ Gestão de projetos } \\
\hline Resultado de inovação & $\begin{array}{l}\text { Identificado }(0=\text { não; } 1= \\
\text { sim) }\end{array}$ & Trecho do relato & Termo de identificação \\
\hline \multicolumn{4}{|l|}{$\begin{array}{l}\text { Melhoria na entrega e/ou } \\
\text { qualidade dos serviços }\end{array}$} \\
\hline \multicolumn{4}{|l|}{$\begin{array}{c}\text { Melhoria da gestão } \\
\text { organizacional }\end{array}$} \\
\hline \multicolumn{4}{|l|}{$\begin{array}{l}\text { Melhoria da imagem e } \\
\text { relações institucionais }\end{array}$} \\
\hline $\begin{array}{c}\text { Melhoria do clima } \\
\text { organizacional }\end{array}$ & & & \\
\hline
\end{tabular}


Anexo C - Consulta efetuada sobre o modelo de inovação no Poder Executivo Federal

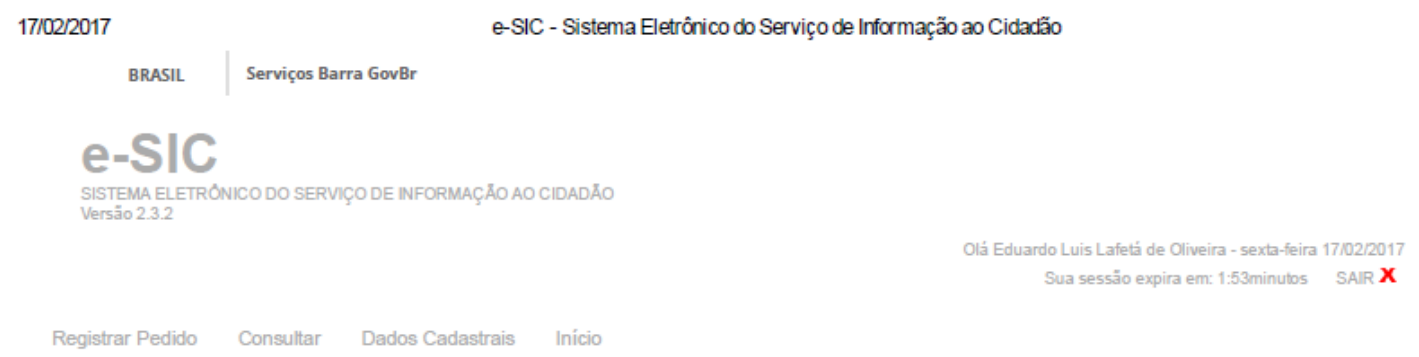

Relatório - Detalhe do Pedido

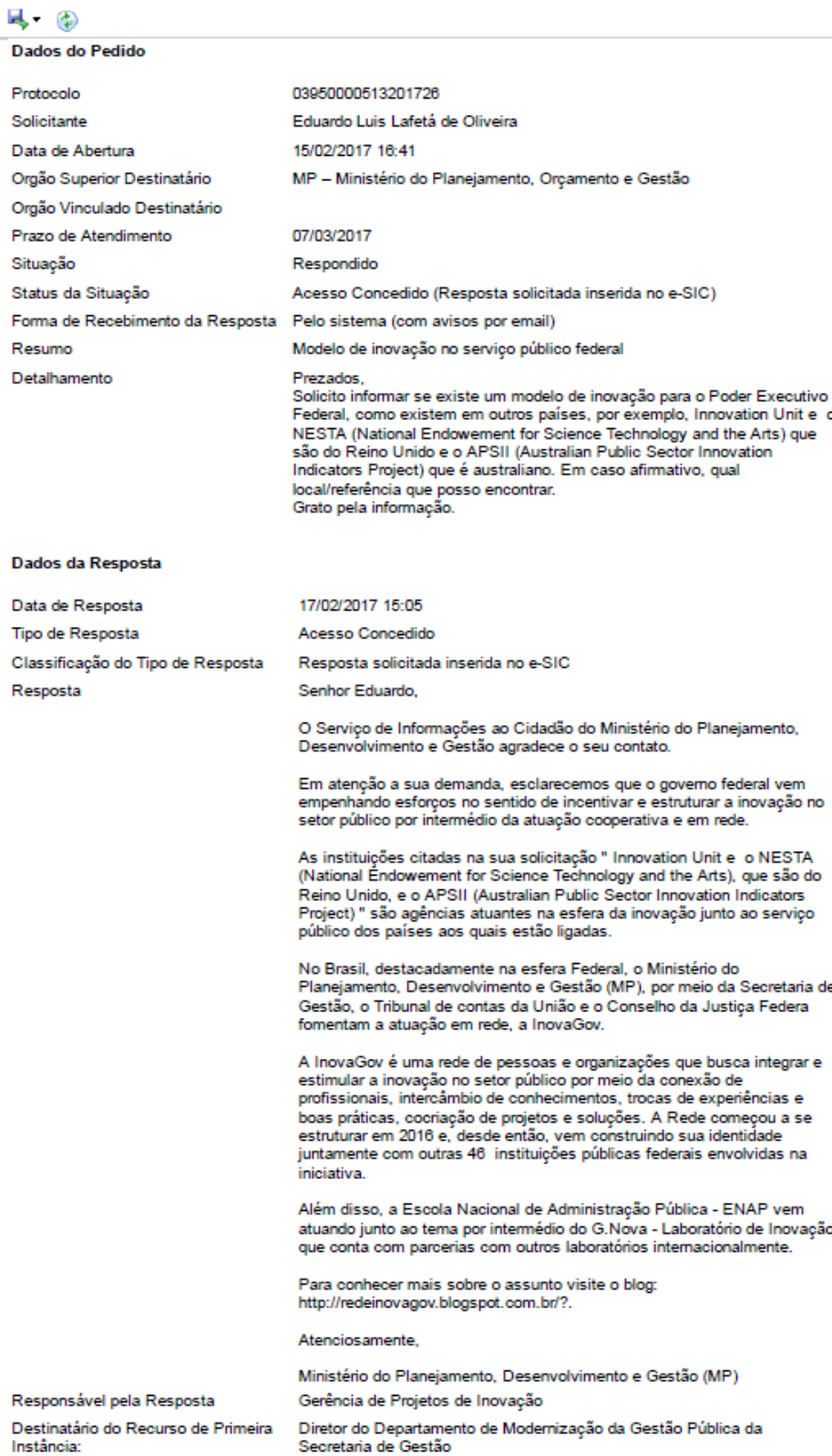


17/02/2017

Prazo Limite para Recurso Classificação do Pedido

Categoria do Pedido

Subcategoria do Pedido

Número de Perguntas

Histórico do Pedido

Data do evento 15/02/2017 16:41

17/02/2017 15:05
e-SIC - Sistema Eletrônico do Serviço de Informação ao Cidadão

01/03/2017

Governo e Política

Administraçäo pública

Responsável

Pedido Registrado para o Órgão MP - Ministério SOLICITANTE

Orçamento e Gestão

MP - Ministério do Planejamento.

Orçamento e Gestão 